\title{
Role of phytoplankton cell size on the competition for nutrients and light in incompletely mixed systems
}

\author{
Onur Kerimoglu*, Dietmar Straile, Frank Peeters \\ Limnological Institute, University of Konstanz, D-78464 Konstanz, Germany
}

\begin{abstract}
A B S T R A C T
We investigate the effects of algal cell size on the competition for nutrients and light in an incompletely mixed water column, employing a spatially explicit variable internal stores approach and previously published allometric scaling relationships for modeling phytoplankton growth. We analyze the interplay between the size-dependent vertical assimilation and uptake profiles and the role of environmental settings such as mixing intensity, nutrient loading and background turbidity for the outcome of competition. Our results suggest that a potentially beneficial factor for resource competition in spatially heterogeneous systems is a low ratio of subsistence nutrient quota to the maximal quota, $q_{\min } / q_{\max }$, which is a decreasing function of cell size according to allometric relationships. Environmental parameters such as mixing intensity and nutrient availability are shown to modulate the relevance of the $q_{\min } / q_{\max }$ ratio for the competitive outcome and thereby have non-monotonic impacts on the algal size selection. The outcome of competition further depends on the temporal and spatial variability of mixing. In particular, the presence of a metalimnion with low diffusivity and periodic perturbation of the depth of the metalimnion strongly influences the relative success of differently sized algae. This suggests that the anticipated reduction in wind induced mixing events due to climate warming will have context-dependent consequences for algal size selection.
\end{abstract}

\section{Introduction}

Size structure of algal communities is recognized to have important implications for biogeochemical fluxes (Richardson and Jackson, 2007). Investigation of the mechanisms contributing to the emergence of size structures is therefore of major importance for a better understanding of the global carbon cycle. Cell size affects a number of functional traits of phytoplankton species, thus, their fitness in a given habitat (Litchman and Klausmeier, 2008). Accordingly, observations indicate significant relationships between phytoplankton size structure and physical variables, such as water column stability (Li, 2002; Winder et al., 2009) and mesoscale vertical motion (Rodriguez et al., 2001), which, in turn, results in macro-ecological patterns such as dominance by small cells in the tropics and large cells in the coastal or sub-polar upwelling zones (Follows et al., 2007).

The Droop model (Droop, 1973), which allows variation of internal nutrient stores, hence also known as variable internal stores model, is commonly recognized to be the appropriate

\footnotetext{
* Correspondence to: Limnologisches Institut, Mainaustrasse 252, 78464 Konstanz, Germany. Tel.: 49753188 3552; fax: 497531883533.

E-mail addresses: Kerimoglu.O@googlemail.com (0. Kerimoglu).

Dietmar.Straile@uni-konstanz.de (D. Straile).

Frank.Peeters@uni-konstanz.de (F. Peeters).
}

framework to study algal resource competition (Grover, 1991a; Litchman et al., 2009; Smith and Kalff, 1982; Stolte and Riegman, 1995; Verdy et al., 2009). Especially for algae growing in habitats subject to temporal heterogeneity, particular traits such as nutrient affinity, storage capacity or growth velocity (sensu Sommer, 1985) were shown to be critically important for the outcome of competition in laboratory and modeling studies (Sommer, 1985; Grover, 1991b). Explicit consideration of these different traits is possible by considering uptake and assimilation processes separately as in the variable internal stores model approach. Among other parameters, maximum storage capacity, $q_{\max }$, which increases with cell size (Litchman et al., 2009; Montagnes and Franklin, 2001) has been recognized to provide advantages in temporally variable environments by allowing sustained growth when the external nutrients are depleted (Grover, 1991a; Litchman et al., 2009; Sommer, 1985).

Resource competition in an environment characterized by uniform distribution of resources is well understood (Tilman, 1980), relative to that in environments characterized by temporal (Klausmeier; 2008) and spatial (Ryabov and Blasius, 2011) heterogeneities. In deep water bodies, light intensity changes substantially throughout the water column. For such systems in which at least one of the essential resources is not homogeneously distributed, the resource supply ratio theory (Tilman, 1980) becomes inaccurate as the outcome of competition depends on system 
parameters such as absolute resource supply rates, background turbidity and depth of the water column (Huisman and Weissing, 1995). Incomplete mixing makes the problem particularly challenging, as the analytical solutions become inaccessible even for the competition for light as the single limiting resource, where the light profile interactively evolves with the biomass profiles of competing species which are continuously redistributed throughout the water column as a function of mixing intensity (Huisman et al., 1999a, b). Competition for dissolved nutrients and light found in opposite gradients in poorly mixed systems (Klausmeier and Litchman, 2001) has been recently addressed (Ryabov and Blasius, 2011; Ryabov et al., 2010; Yoshiyama et al., 2009; Huisman et al., 2006). These studies primarily focused on the trade-off between nutrient and light competitive abilities, and sought mechanisms that affect the optimal vertical distribution of species and their competitive abilities.

Increasing turbulent mixing is predicted to favor larger cells by reducing their disadvantage for their lower nutrient acquisition capacity in nutrient limited conditions (Raven, 1998) via enhancing the supply rate of dissolved nutrients from the hypolimnion (Falkowski and Oliver, 2007). Vertically resolved numerical models with flexible elemental stoichiometry of algal cells suggest that the cell nutrient quota profiles follow gradients similar to that of the familiar nutrient profiles in the poorly mixed systems where nutrients are introduced from the bottom: close to the subsistence levels at the surface, and at maximum levels within the hypolimnion (Jäger et al., 2010; Salihoglu et al., 2008; Tett et al., 1986). This pattern of elemental compositions has also been observed in the in situ seston nutrient ratios (Tett et al., 1986; Elser and George, 1993). Effects of these theoretically predicted and empirically verified spatial heterogeneities in the physiological condition of populations on their competitive abilities started receiving attention only very recently (Grover, 2009; Hsu et al., 2010).

In this study, we investigate resource competition dynamics in an incompletely mixed water column employing a vertically resolved, multi-species cell-quota model. We employ a complete set of scaling relationships provided by Litchman et al. (2009) to determine 5 different parameter values related to algal resource uptake and assimilation processes. We first develop a mechanistic understanding of the influence of size dependent differences in physiological parameters on algal competitive abilities within a water column where the resources are heterogeneously distributed. These analyses point to a mechanism whereby a larger storage capacity relative to the subsistence quota results in a higher rate of decrease in the nutrient limitation along the water column, which can constitute a decisive competitive advantage depending on environmental parameters. Then we systematically investigate the competition outcomes under various environmental settings, results of which suggest that changes in system parameters such as nutrient concentrations and background turbidity can have opposite effects on the outcome of competition at different mixing intensities. We also consider the effects of vertical variability in the mixing intensities and show that the presence of a thermocline with a low permeability can have dramatic effects on the outcome of competition. Finally, we check the effects of deepening of the mixed layer depth at different periodicities and illustrate contrasting effects of mixing periodicity on the algal size selection, that depend on background mixing intensity and nutrient concentrations. Overall, our numerical analyses point to novel and intriguing aspects of the role of cell size on algal resource competition.

\section{The model}

We consider a vertical water column, where depth $z$ indicates the depth between the surface, $z=0$ and the maximum depth, $z=z_{\max }$. A system of five partial differential equations (PDE's) describes the vertical distributions of the carbon biomass $\left(A_{i}\right)$ and particulate nutrients bound in phytoplankton $\left(B_{i}\right)$ for two species ( $i=S, L$ for small and large) and dissolved nutrients $(N)$ within the water column:

$$
\begin{aligned}
& \frac{\partial A_{i}}{\partial t}=p_{i}\left(I, q_{i}\right)\left(1-l_{r, i}\right) A_{i}-l_{d, i} A_{i}-s_{i} \frac{\partial A_{i}}{\partial z}+\frac{\partial}{\partial z}\left(D(z) \frac{\partial A_{i}}{\partial z}\right) \\
& \frac{\partial B_{i}}{\partial t}=v_{i}\left(N, q_{i}\right) A_{i}-\left(p_{i} l_{r, i}+l_{d, i}\right) B_{i}-s_{i} \frac{\partial B_{i}}{\partial z}+\frac{\partial}{\partial z}\left(D(z) \frac{\partial B_{i}}{\partial z}\right) \\
& \frac{\partial N}{\partial t}=\sum_{i} \gamma_{r, i} l_{r, i} p_{i}\left(I, q_{i}\right) A_{i} q_{i}+\sum_{i} \gamma_{d, i} l_{d, i} B_{i}-\sum_{i} v_{i}\left(N, q_{i}\right) A_{i}+\frac{\partial}{\partial z}\left(D(z) \frac{\partial N}{\partial z}\right)
\end{aligned}
$$

where $p_{i}$ is the production rate as a function of light intensity and nutrient quota defined as $q_{i}=B_{j} / A_{i}, l_{r, i}$ is the production dependent respiration rate, $l_{d, i}$ is the background death rate, $s_{i}$ is the sinking velocity of species $i, D(z)$ is the turbulent diffusion coefficient at depth $z, v_{i}$ is the uptake rate as a function of $N$ and $q_{i}$ and $\gamma_{r, i}$ and $\gamma_{d, i}$ are the dissolved portion of, respectively, the phytoplankton excretions and dead cells. All state variables and parameters are defined in Table 1.

It is assumed that phytoplankton excrete dissolved nutrients at the same specific rate as they respire carbon (i.e., $p_{i} l_{r, i}$ ). It is further assumed that half of the nutrients released due to excretion and death of phytoplankton are in dissolved form $\left(\gamma_{r, i}=\gamma_{d, i}=0.5\right.$, for $i=S, L$, Eq. (3)), have identical stoichiometry as the living cells they originate from $\left(q_{i}\right)$ and are immediately mineralized and incorporated into the dissolved nutrient pool, while the rest is assumed to be in particulate form and simply disappear from the system (sedimented and mineralized below $z_{\max }$, which we do not consider explicitly).

Light intensity, $I$, and quota, $q_{i}$, of a single limiting nutrient (Droop, 1973) is assumed to interact multiplicatively (Rhee and Gotham, 1981) to determine the production of new biomass, $p_{i}\left(I, q_{i}\right)$ :

$p_{i}\left(I, q_{i}\right)=\mu_{\infty, i}\left(\frac{q_{i}-q_{\min , i}}{q_{i}} \frac{I}{I+K_{I, i}}\right)$

where, $\mu_{\infty, i}$ is the hypothetical growth rate of species $i$ at infinite cell quota $\left(q_{i}=\infty\right), q_{\min , i}$ is the subsistence cell quota at which growth ceases and $K_{l, i}$ is the half saturation constant of light dependent growth

Light intensity decreases exponentially from $I=I_{\text {in }}$ at the surface, $z=0$, to depth $z$, following Lambert-Beer's law:

$I(z)=I_{\text {in }} \exp \left[-k_{b g} z-k \sum_{i} \int_{0}^{z} A_{i}\left(t, z^{\prime}\right) d z^{\prime}\right]$

where $k_{b g}$ and $k$ are the background turbidity and the specific light absorption coefficient of the phytoplankton, respectively.

The nutrient uptake rate, $v_{i}(N, q)$ follows Michelis-Menten kinetics:

$v_{i}(N, q)=v_{\max , i}(q) \frac{N}{N+K_{N, i}}$

where $K_{N, i}$ is the half saturation constant for nutrient uptake of species $i$ and the maximum uptake rate, $v_{\text {max }, i}$, is a function of $q_{i}$ (Morel, 1987), decreasing linearly from $v_{\operatorname{maxH}, i}$, at $q_{i}=q_{\min , i}$ to 0 , at $q_{i}=q_{\max , i}$, such that the nutrient quotas cannot exceed the $q_{\max , i}$ (Jäger et al., 2010)

$v_{\max , i}(q)=v_{\max , i}\left(\frac{q_{\max , i}-q_{i}}{q_{\max , i}-q_{\min , i}}\right)$ 
Table 1

Model parameters. Values were chosen from the typical ranges observed in nature and are similar to those used in similar models e.g., Huisınan et al. (2006) and Jäger et al.( 2010).

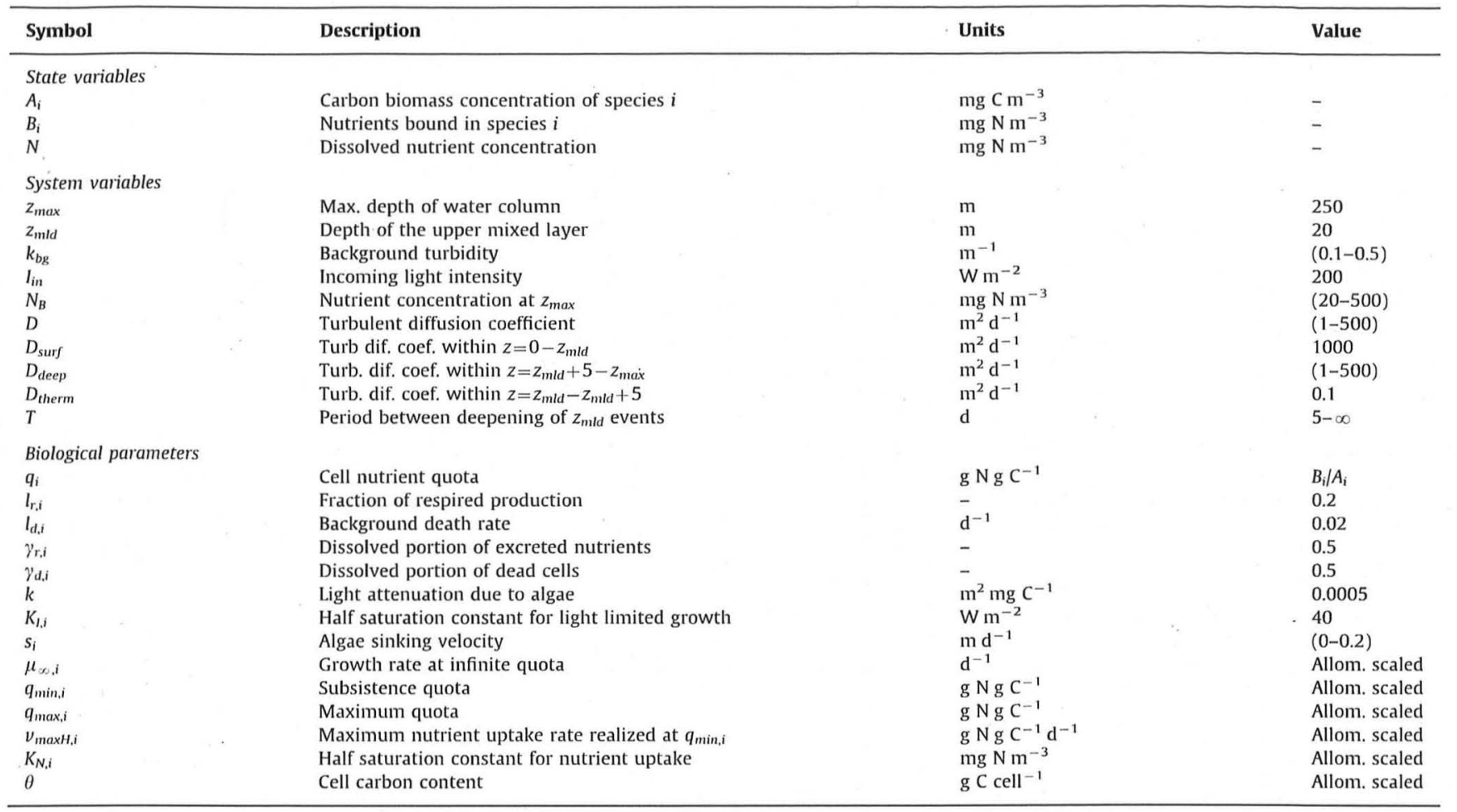

\section{Table 2}

Allometric scaling relationships for nitrate limited marine diatoms, provided by Litchman et al. (2009). The size dependent parameters were calculated according to $\log _{10}($ par $)=a+b \log _{10}(V)$, where $V$ is the volume of the cell. In case of $q_{\min , i}, q_{\max , i}$ and $v_{\max , i}$, which were originally provided in cell-specific units, carbon-specific units were obtained by dividing the resultant parameter value to the carbon content $\theta$, calculated also from the allometric relationship $\log (0)=-0.314+0.712 \log (V)$, as given by Strathmann (1967). The final parameter values used for nutrient source as nitrogen and the species with volumes $V=10^{2}$ and $10^{4} \mu m^{3}$ which are often mentioned throughout the text are also shown.

\begin{tabular}{|c|c|c|c|c|c|c|}
\hline \multirow[t]{2}{*}{ Parameter } & \multicolumn{2}{|c|}{ Allom. coeff.'s } & \multirow[t]{2}{*}{ Original unit } & \multirow[t]{2}{*}{ Final unit } & \multicolumn{2}{|c|}{ Final value } \\
\hline & $a$ & $b$ & & & $V=10^{2}$ & $V=10^{4}$ \\
\hline$\mu_{\infty, i}$ & 0.74 & -0.14 & $\mathrm{~d}^{-1}$ & $\mathrm{~d}^{-1}$ & 2.88 & 1.51 \\
\hline$q_{\min , i}$ & -8.59 & 0.56 & $\mu \mathrm{mol} \mathrm{N}$ cell $^{-1}$ & $\mathrm{~g} \mathrm{~N} \mathrm{~g} \mathrm{C}^{-1}$ & 0.0245 & 0.0121 \\
\hline$q_{\max , i}$ & -8.39 & 0.81 & $\mu \mathrm{mol} \mathrm{N}$ cell $^{-1}$ & $\mathrm{~g} \mathrm{~N} \mathrm{~g} \mathrm{C}^{-1}$ & 0.123 & 0.193 \\
\hline$v_{\max , i}$ & -7.8 & 0.67 & $\mu \mathrm{mol} \mathrm{N}$ cell ${ }^{-1} \mathrm{~d}^{-1}$ & $\mathrm{~g} \mathrm{Ng} \mathrm{C}^{-1} \mathrm{~d}^{-1}$ & 0.25 & 0.21 \\
\hline$K_{N}$ & -0.49 & 0.17 & $\mu \mathrm{mol} \mathrm{N}-1 \mathrm{~L}^{-1}$ & $\mathrm{mg} \mathrm{N} \mathrm{m}{ }^{-3}$ & 9.91 & 21.68 \\
\hline
\end{tabular}

\subsection{Model implementation}

We assume no-flux boundary conditions at the surface $(z=0)$ for all state variables (Eqs. (1)-(3)). The boundary conditions at the maximum depth, $z=z_{\max }$, describe the interactions between the dynamically modeled water column and a static layer beneath. For the dissolved nutrients, we assume Dirichlet boundary conditions at the bottom of the dynamic layer, $N\left(z_{\max }\right)=N_{B}$, where $N_{B}$ is a parameter intensively assessed for its effects on the competition dynamics in this study. The diffusive flux of phytoplankton biomass and bound nutrients is zero at $z=z_{\max }$. When sinking rate, $s_{i}$, is larger than zero, the phytoplankton biomass and bound nutrients sink out the system. As initial conditions, we assume dissolved nutrient concentration of $N=N_{B}$ and phytoplankton biomass concentration of $1 \mathrm{mg} \mathrm{C} \mathrm{m}^{3}$ for both competing species, and that the nutrient quotas are at their maximum $\left(B_{i}=A_{i} q_{\max , i}\right)$, all uniform throughout the water column, unless otherwise mentioned. The advection terms were discretized by a third order upwind scheme and the diffusion terms by a secondorder scheme, with a $0.25 \mathrm{~m}$ spaced uniform grid. The resulting system of ordinary differential equations was solved using MatLab's stiff solver ODE15s.

\subsection{Allometric scaling of parameters}

Parameters related to nutrient uptake and assimilation of algae depends on algal cell size (e.g., Litchman et al., 2009; Sunda and Hardison, 2010; Irwin et al., 2006). We use allometric relationships for $\mathrm{N}$-limited marine diatoms (Table 2) provided by Litchman et al. (2009) to calculate $\mu_{\infty}, q_{\min }, q_{\max }, v_{\operatorname{maxH}}$ and $K_{N}$ for two differently sized algal species (cell volumes: $10^{2}$ and $10^{4} \mu \mathrm{m}^{3}$ ). Allometric coefficients provided by Strathmann (1967) were employed for the conversion from cell-specific to carbon-specific units (Table 2). All other parameters (e.g., light affinity and absorption) are assumed to be identical for the competing species. 
2.3. Spatial and spatio-temporal heterogeneities in the mixing intensity

In addition to the simulations in which we assume constant $D$ throughout the water column, we considered two structurally different vertical profiles of $D$ to describe stratification. The first profile consists of an intensely mixed surface layer $\left(D_{\text {surf }}=1000 \mathrm{~m}^{2} \mathrm{~d}^{-1}\right.$ ) extending to a depth specified by a predetermined mixed layer depth, $z_{\text {mld }}$ (unless otherwise mentioned $z_{\text {mld }}=20 \mathrm{~m}$ ), and a deep layer with a lower mixing intensity, as determined by the parameter $D_{\text {deep }}$. Such 2-layer structuring has been recently shown to have important consequences on phytoplankton competition dynamics (Ryabov et al., 2010; Yoshiyama et al., 2009). In order to obtain a smooth transition between these two layers, mixing intensities within the first $5 \mathrm{~m}$ below $z_{\text {mld }}$ are calculated by linear interpolation of the base 10 logarithm values, in order to account for the logarithmic scaling of $D$ values observed in nature (e.g., Li, 1973). This mixing profile consisting of 2 layers will be called the UML in short, referring to an upper mixed layer. The second mixing profile considers the presence of a thermocline, assumed here as a $5 \mathrm{~m}$ thick layer with very poor mixing $\left(D_{\text {therm }}=0.1 \mathrm{~m}^{2} \mathrm{~d}^{-1}\right)$ between the intensely mixed surface layer and poorly mixed deep layer. Such 3-layer structuring can result in catastrophic transitions between surface and subsurface phytoplankton growth (Yoshiyama and Nakajima, 2002). In order to obtain smooth transitions between different layers, the mixing intensities within the $0.5 \mathrm{~m}$ centered around the boundaries were calculated by linear interpolation of the base 10 logarithm values. Thermal stratification of water bodies can be perturbed by wind forcing, which can lead to a deepening of the upper mixed layer and entrainment of hypolimnetic water to the epilimnion (Blanton, 1973; Reynolds, 1989). We approximate the effects of this process on the vertical mixing profile by considering a transient deepening of the mixed layer depth, $z_{m l d}$, by $10 \mathrm{~m}$ for a duration of 2 days, occurring with a prescribed periodicity $T$. The transition occurs within 1 day, during which, the diffusivities at each depth level are calculated by linear interpolation of the base 10 logarithm values of diffusivities known at the start and end of the day.

\subsection{Outcome of competition}

In 2-species experiments, determination of the outcome of competition can sometimes become problematic, as a lower abundance of one of the competing species at the end of a certain simulation time can either imply an ultimate exclusion or stabilization at a non-zero equilibrium, which would mean co-existence. On the other hand, being able to grow when rare, or the invasibility of each of the species within a community, is considered to be a reliable measure of fitness (MacArthur and Levins, 1967; Metz et al., 1992). Therefore, for systematically assessing the competition outcome under various environmental conditions, mutual invasion experiments were conducted. In the conventional invasibility analysis, the sign of the initial net growth rate of each species when rare (e.g., when perturbed to a low density, or when introduced to the system as an invader) constitutes the criteria for competitive exclusion or co-existence (MacArthur and Levins, 1967; Metz et al., 1992; Geritz et al., 1998; Smith and Price, 1973). However, according to the variable internal stores model, the growth rate at a given time is determined by the internally stored nutrients, rather than the external availability of nutrients. Therefore, in a water column where the resources are nonuniformly distributed, the ultimate success of an invader can be known only after its quota profile reaches equilibrium.

Invasibility analyses were conducted as follows: first, a monoculture of resident species was simulated for 20,000 days. Then the nutrient and light profiles obtained at the end of the resident simulation was used to drive a simulation of an invader species (Eqs. (1) and (2), i.e., no feedback to the environment), assuming initial conditions of vertically homogeneous biomass and maximum nutrient quotas $\left(q_{i}=q_{\max , i}\right)$. These initial conditions lead to transient dynamics lasting for 100-300 days (depending mostly on the diffusivity), after which the quota profiles and consequently the net per capita growth rates approach a steady vertical distribution. At day 800 , we checked the signs of the change in biomass at each grid point, and considered any positive change as a successful invasion. Chesson (2000) employs the sign of the average regional growth rate as the invasibility criterion. The results were identical when we checked the average rate of changes throughout the water column at day 800 , noting however that in our case the system is not closed in case of non-zero sinking rates, violating the underlying assumption for the use of average regional growth rate. A similar protocol of forcing the invader quota profiles until the equilibrium in a spatially structured environment prior to checking the growth rates was applied in (Grover, 2009). The competitive outcomes determined by means of the invasibility analysis were all reproduced by the 2-species experiments. For confirming extinction of a species when competitive exclusion was predicted by the invasion experiments, 2-species experiments required variable amount of simulation times (up to 25,000 days) depending on the particular environmental setting.

\section{Results}

The outcome of algal competition is sensitive to the turbulent diffusion coefficient, $D$, and the nutrient concentration at the bottom of the water column, $N_{B}$ (Fig. 1). As a result of the initially full quotas and the homogeneous distribution of dissolved nutrients, the algal populations go through a transient bloom for a duration depending mainly on the mixing intensity. After the transient bloom, the large species $\left(10^{4} \mu \mathrm{m}^{3}\right)$ was competitively excluded by the small species $\left(10^{2} \mu \mathrm{m}^{3}\right)$ in environments that are characterized by an intermediate mixing intensity and a low nutrient concentration at the bottom
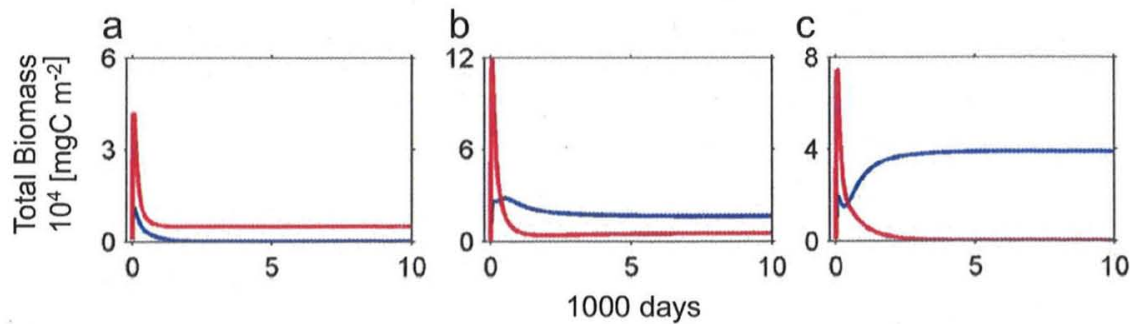

Fig. 1. Time series of 2-species simulation of a large (blue) and small (red) species with cell volumes of $10^{4}$ and $10^{2} \mu \mathrm{m}^{3}$, respectively, under following environmental settings: (a) $N_{B}=20 \mathrm{mg} \mathrm{N} \mathrm{m}^{-3}, D=10 \mathrm{~m}^{2} \mathrm{~d}^{-1}$, (b) $N_{B}=80 \mathrm{mg} \mathrm{N} \mathrm{m}^{-3}, D=10 \mathrm{~m}^{2} \mathrm{~d}^{-1}$, (c) $N_{B}=20 \mathrm{mg} \mathrm{N} \mathrm{m}^{-3}, D=50 \mathrm{~m}^{2} \mathrm{~d}^{-1}$. Background turbidity, $k_{b g}=0.1 \mathrm{~m}^{-1}$, and sinking velocity, $s_{i}=0.2 \mathrm{~m} \mathrm{~d}^{-1}$, for both species. 
(Fig. 1a). A relatively higher nutrient concentration at the bottom promoted the large species, although the small species still persisted, i.e., two species co-existed (Fig. 1b). The large species dominated in a relatively more rapidly mixed environment even when $N_{B}$ was as low as in the first case (Fig. 1c).

The species considered in these experiments differ with respect to 5 size-dependent parameters relating the nutrient uptake and assimilation capacities of each species (Table 2). For spatially uniform environments, these parameters can be used to derive the steady state external resource concentrations, $R^{*}$ (Ducobu et al., 1998), and the competition outcome can be analytically deduced based on resource supply ratios (Tilman, 1980). When the physiological processes and parameters considered here are employed in a conventional well-mixed chemostat model, the equilibrium nutrient concentration, $N^{*}$, of the small species turns out to be always smaller than that of the large species (Appendix A), implying that the small species is unconditionally dominant in the absence of heterogeneities in the distribution of nutrients according to the resource competition theory (Tilman, 1980). This result is in agreement with Litchman et al. (2009), who suggested that small cell sizes are selected in the absence of temporal variability in nutrient supply, based on the evolutionary stable strategy sizes suggested by a chemostat model similar to the one employed in Appendix A. In contrast to the predictions of the well-mixed chemostat models, invasibility analysis conducted with the vertically resolved model (Eqs. (1)-(3)) suggests that large species can be competitively dominant in the absence of temporal variability as well, depending on the environmental settings (Fig. 1).

\subsection{Mechanisms of competition}

In order to gain some insight into the mechanisms governing the dynamics of competition for the scenarios considered above
(Fig. 1), we inspect the final vertical profiles of a number of variables reached at day 10,000 of the 2 -species simulations (Fig. 2). At day 10,000 , dissolved nutrient concentrations $N$ increase with depth (Fig. $2 \mathrm{a}, \mathrm{h}$ and $\mathrm{o}$ ). The uptake rates $v_{i}$ follow a uni-modal profile (Fig. 2b, i and p), as external nutrient concentrations at the surface are low and nutrient storages $q_{i}$ asymptotically approach $q_{\max }$ with increasing depth (Fig. 2c, j and q). The uptake rates of the small species exceed those of the large species at shallower regions where the external nutrient concentrations are low (Fig. $2 \mathrm{~b}, \mathrm{i}$ and p), as the $K_{N}$ (half saturation constant for nutrient uptake) of the small species is lower than that of the large species (Table 2). The 'production capacity set by the light', cap $_{\text {, }}$ defined as (Eq. (4))

$\operatorname{cap}_{I}=\left(\frac{I}{I+K_{I, i}}\right)$

is identical for competing species as $K_{I, i}$ is assumed to be independent of cell size (Fig. 2d, k and r). However, the vertical profiles of 'production capacity set by the nutrients', cap $_{N, i}$ (Eq. (4))

$\operatorname{cap}_{N, i}=\left(\frac{q_{i}-q_{\min , i}}{q_{i}}\right)$

differ between the competing species (Fig. $2 \mathrm{~d}, \mathrm{k}$ and r). The difference between the nutrient capacities at a given depth level is

$\operatorname{cap}_{N, L}(z)-\operatorname{cap}_{N, S}(z)=\frac{q_{\min , S}}{q_{S}(z)}-\frac{q_{\min , L}}{q_{L}(z)}$

At the surface where $q_{i} \rightarrow q_{\text {min, }, \text {, }}$ the nutrient capacities approach 0 , and hence the difference between the capacities. At deep layers where $q_{i} \rightarrow q_{\max , i}$, the large species have a higher nutrient capacity as

$\frac{q_{\min , S}}{q_{\max , S}}>\frac{q_{\min , L}}{q_{\max , L}}$

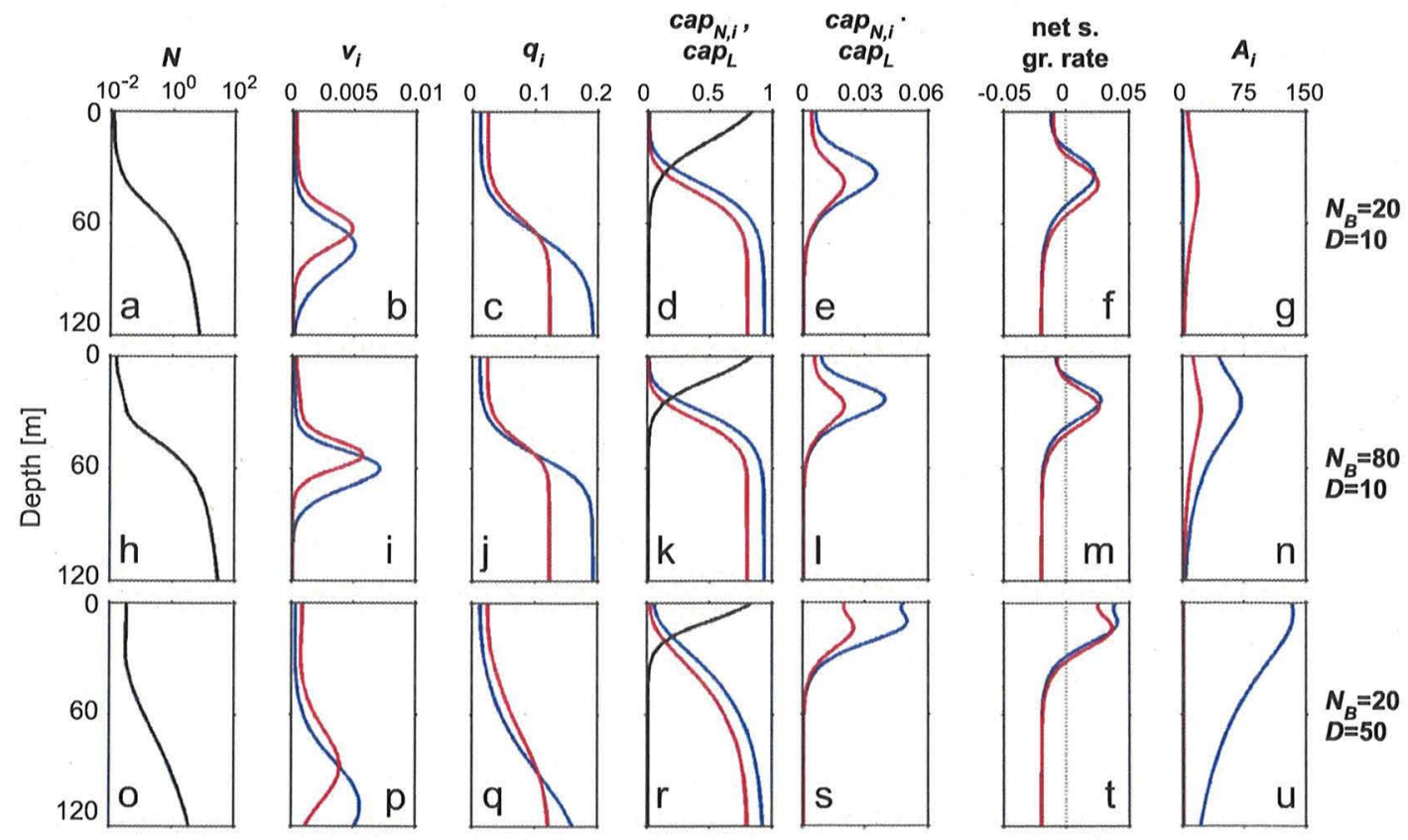

Fig. 2. Vertical profiles at the day 10,000 of long term competition experiments shown in Fig. 1, when the sinking velocity, $s_{i}=0.2$, for both species and (a-g) $N_{B}=20$ mg $\mathrm{N} \mathrm{m}^{-3}, D=10 \mathrm{~m}^{2} \mathrm{~d}^{-1}$, (h-n) $N_{B}=80 \mathrm{mg} \mathrm{N} \mathrm{m} \mathrm{m}^{-3}, D=10 \mathrm{~m}^{2} \mathrm{~d}^{-1}$. (o-u) $N_{B}=20 \mathrm{mg} \mathrm{N} \mathrm{m}^{-3}, D=50 \mathrm{~m}^{2} \mathrm{~d}^{-1}$ showing (a, h,o) dissolved nutrient concentration, $N\left(\mathrm{mg} \mathrm{N} \mathrm{m} \mathrm{m}^{-3}\right.$, note the logarithmic scale); (b, i, p) nutrient uptake rate, $v_{i}\left(\mathrm{~g} \mathrm{~N} \mathrm{~g} \mathrm{C}^{-1} \mathrm{~d}^{-1}\right) ;(\mathrm{c}, \mathrm{j}, \mathrm{q})$ surplus nutrient quota, $q_{i}-q_{\min , i}(\mathrm{~g} \mathrm{~N} / \mathrm{g} \mathrm{C}$ ); (d, k, r) production capacity imposed by nutrients, $\operatorname{cap}_{N, i}$, and by light, $\operatorname{cap}_{L}$ (see Eq. (4), note that $\operatorname{cap}_{L}$ is identical for both species, therefore shown in black); (e, l, s) ultimate capacity given by the product of $\operatorname{cap}_{N, i}$ and $\operatorname{cap}_{L} ;(\mathrm{f}, \mathrm{m}, \mathrm{t})$ net specific growth rate $\left(\mathrm{d}^{-1}\right)$ obtained by subtracting background and production dependent losses from specific production ( $p_{i}-l_{p, i} p_{i}-l_{b, i}$ see Eq. (1)); $(\mathrm{g}, \mathrm{n}, \mathrm{u})$ concentration of algal biomass, $A_{i}\left(\mathrm{mg} \mathrm{C} \mathrm{m} \mathrm{m}^{-3}\right)$ of a large (blue) and small (red) species with cell volumes of $10^{4}$ and $10^{2} \mu \mathrm{m}^{3}$, respectively. 
which is a consequence of the higher allometric exponent of $q_{\max }$ than that of $q_{\min }$ (Table 2).

Our numerical simulations further illustrate that with increasing depth, the rate of deviation of $q_{\min , L} / q_{L}$ from 1 across depth is higher than that of $q_{\min , S} / q_{\mathrm{S}}$ (Fig. $2 \mathrm{~d}$, k and r), so that $\operatorname{cap}_{N, L}-\operatorname{cap}_{N, S}$ (Eq. (10)) is always positive, i.e., the large species is less affected by nutrient limitation than the small species throughout the water column. Consequently, the ultimate production capacity, $\operatorname{cap}_{L} \operatorname{cap}_{N, i}$, of the large species is higher than that of the small species in the entire water column (Fig. 2e, 1 and s). As a result of opposing gradients of nutrient and light capacity curves, the ultimate capacity profiles display a uni-modal profile along depth (Fig. 2e, 1 and s). To obtain the specific production rate, the ultimate capacity is multiplied by the maximum growth rate, which decreases with cell size. Finally, subtracting the productivity specific and background losses from the specific production rate gives the net specific growth rate (Fig. $2 \mathrm{f}, \mathrm{m}$ and $\mathrm{t}$ ). The net specific growth rate of the large species exceeds that of the small species towards the surface, and vice versa. Finally, the competition is resolved (Fig. 2g, n and u) through a complex feedback loop between the vertical profiles of dissolved nutrients, uptake rates, quotas, net growth rates, material transport terms, biomasses and light availability.

Increasing the bottom nutrient concentration, $N_{B}$, from 20 to $80 \mathrm{mg} \mathrm{N} \mathrm{m}^{-3}$ and increasing the mixing intensity, $D$, from 10 to $50 \mathrm{~m}^{2} \mathrm{~d}^{-1}$ results in higher $N$ concentrations at the surface (Fig. 2a, h and o). The uptake rates increase with increasing $N$ concentrations at the surface layers, while the small species have higher nutrient uptake rates within this zone (Fig. 2b, i and p).
Importantly, increasing $N_{B}$ and $D$ cause $q_{\min , i} / q_{i}$ of both species to deviate from 1 closer to the surface (Fig. 2c, j and q). This, in turn, results in reduction of nutrient limitation for both species and the difference between the nutrient limitation of competing species to become substantial already at the shallow layers (Fig. 2d, k and r). Interaction of higher nutrient capacities at the surface with abundant light, in turn, results in a larger difference between the ultimate capacities ( $\operatorname{cap}_{N, i} C a p_{L}$ ) of large and small species (Fig. 2e, 1 and s). If the ultimate capacity advantage of the large species becomes sufficient, their low maximal growth rate disadvantage can be overcompensated, making them co-exist with or outcompete the small species (Fig. $2 \mathrm{n}$ and $\mathrm{u}$ ). This analysis reveals that the effects of $N_{B}$ and $D$ on the competition outcome occurs through formation of the vertical quota profiles, hence, positioning of the nutrient capacity advantage of the large cells, which determines the yield of the interaction between the nutrient capacity curves and the light capacity curve.

\subsection{Outcome of competition across different environmental settings}

The outcome of competition depends not only on $N_{B}$ and $D$, for which we inspect this dependence for a systematic grid of values, but also on additional parameters such as the background turbidity $k_{b g}$ and the sinking rate $s_{i}$ (Fig. 3 ). In the first scenario where $s_{i}=0.2 \mathrm{~m} \mathrm{~d}^{-1}$ and $k_{\mathrm{bg}}=0.1 \mathrm{~m}^{-1}$ as in Figs. 1 and 2, small cells are the winners in environments characterized by low nutrient concentrations and low mixing rates (Fig. 3a). The large species becomes dominant at intermediate mixing intensities as a result of upward shifting of the nutrient capacity advantage
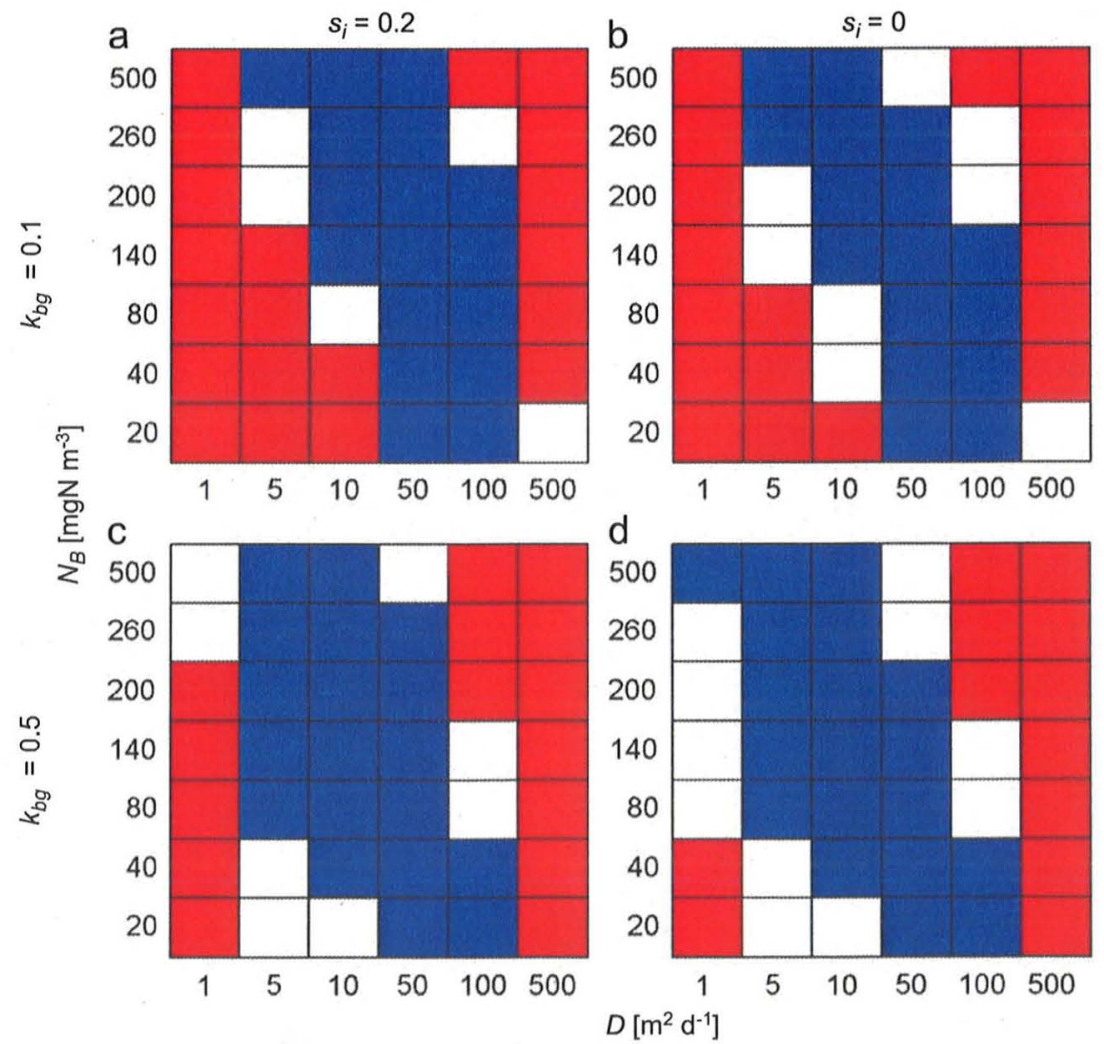

Fig. 3. Results of mutual invasibility experiments conducted with a large $\left(10^{4} \mu \mathrm{m}^{3}\right)$ and small $\left(10^{2} \mu \mathrm{m}^{3}\right)$ species in the $N_{B}-D$ parameter plane, when (a, c) cells sink with $s_{i}=0.2 \mathrm{~m} / \mathrm{d}$; (b, d) cells are neutrally buoyant; (a, b) background turbidity, $k_{b g}=0.1 \mathrm{~m}^{-1} ;$ (c, d) $k_{b g}=0.5 \mathrm{~m}^{-1}$. Red and blue colored cells indicate dominance by small and large species, respectively. A dominant species successfully invades an environment set by the resident, while its opponent fails to invade the environment set by the dominant species. White cells indicate successful invasion by both large and small species, suggesting coexistence. 
(Section 3.1). At higher mixing intensities light limitation becomes the primary determinant of the outcome of competition. "Critical turbulence", which is defined as the maximum turbulent mixing intensity at which a steady population size can be maintained at a given water column depth and light availability (Huisman et al., 1999) is lower for the large than for the small species because of the lower maximal growth rate of the large species. For all parameter ranges considered in this study, both species can persist as mono-culture species. However, when the small species is the resident, increasing $N_{B}$ and $D$ supports higher biomasses of the small species and reduces the equilibrium light availability by shading. The reduced underwater light intensity lowers the critical turbulence of the large species and results in their extinction when introduced as invaders, if the $D$ of the environment is higher than their critical turbulence.

When the background turbidity is raised to $0.5 \mathrm{~m}^{-1}$ (Fig. 3c and d), small cells are replaced by large cells at low mixing-low nutrient settings while the large cells are replaced by small cells at high mixing-high nutrient settings. Removing sinking (Fig. 3b and d) has consequences mainly at the lower range of mixing intensities in favor of the large species. At intermediate $D$ $\left(5-10 \mathrm{~m}^{2} \mathrm{~d}^{-1}\right)$, the operation and consequences of increasing the background turbidity $k_{b g}$ and removing the sinking term are similar to those of increasing the $N_{B}$ (Fig. 3): first, all these changes cause enhanced light extinction (due to higher algal biomasses in case of $s_{i}=0$ and high $N_{B}$ ), which, as a direct effect, brings disadvantage to the large species by decreasing their ultimate capacity advantage. Second, all these changes result in an upward shift of the transition from low to high nutrient quotas for both species (in case of $s_{i}=0$ and $k_{b g}=0.5$, as an indirect effect of enhanced light extinction, hence steeper reduction of production with depth), thereby increasing the storage advantage of the large species as explained earlier. Overall, the advantages brought to the large species outweigh the disadvantages associated with increasing $N_{B}$, increasing $k_{b g}$ and removing the sinking term (Fig. 3).

\subsection{Vertical heterogeneities in the mixing intensity}

Introducing a thermocline had dramatic consequences on the outcome of competition, while the effects of an UML structuring were relatively modest. This is exemplified in Fig. 4 for a particular environmental setting, in which, $N_{B}=200 \mathrm{mg} \mathrm{N} \mathrm{m}^{-3}$, $k_{b g}=0.1 \mathrm{~m}^{-1}, s_{i}=0.2 \mathrm{~m} \mathrm{~d}^{-1}$ and $D\left(D_{\text {deep }}\right)=50 \mathrm{~m}^{2} \mathrm{~d}^{-1}$. When the diffusivity is homogenous throughout the water column, after an initial bloom, the abundance of the small species gradually declines, while the large species forms a second and larger bloom that asymptotically approaches stable concentrations (Fig. 4a-e). With an UML the temporal dynamics is almost the same as in the homogeneous mixing case but the phytoplankton biomass becomes more uniformly distributed within the UML. As a result of the high transport rates within the surface layer where the stored nutrients are rapidly assimilated (Fig. $4 \mathbf{f}-\mathbf{j}$ ), the depth range of quotas close to $q_{\min }$ is larger in the presence of an UML than in the homogeneous mixing case. Dissolved nutrients get quickly depleted within the upper $100 \mathrm{~m}$ both in the case of homogeneous mixing and UML (not shown). In the presence of a thermocline, entirely different dynamics emerge (Fig. 4k-0): both species form short-lived blooms above the thermocline, during which, the nutrient quotas below the thermocline remain at high levels (Fig. $4 \mathrm{~m}$ and o) since (i) the assimilation rate is very low due to shading by blooms taking place above the thermocline, (ii) the limited mixing intensity within the thermocline prevents the transport of nutrient-depleted cells from the surface. As the quotas are depleted at the surface, the biomasses above the thermocline start declining, elevating the light availability and hence the specific production below the thermocline, which further reduces upward transport of dissolved nutrients (Fig. 41 and $\mathrm{n}$ ). Thus, a rapid phase transition from a surface maximum to a subsurface maximum occurs. Eventually the nutrient capacity advantage of the large species becomes substantial only below the thermocline and is translated to a relatively weak ultimate capacity advantage because of low light availability, which favors

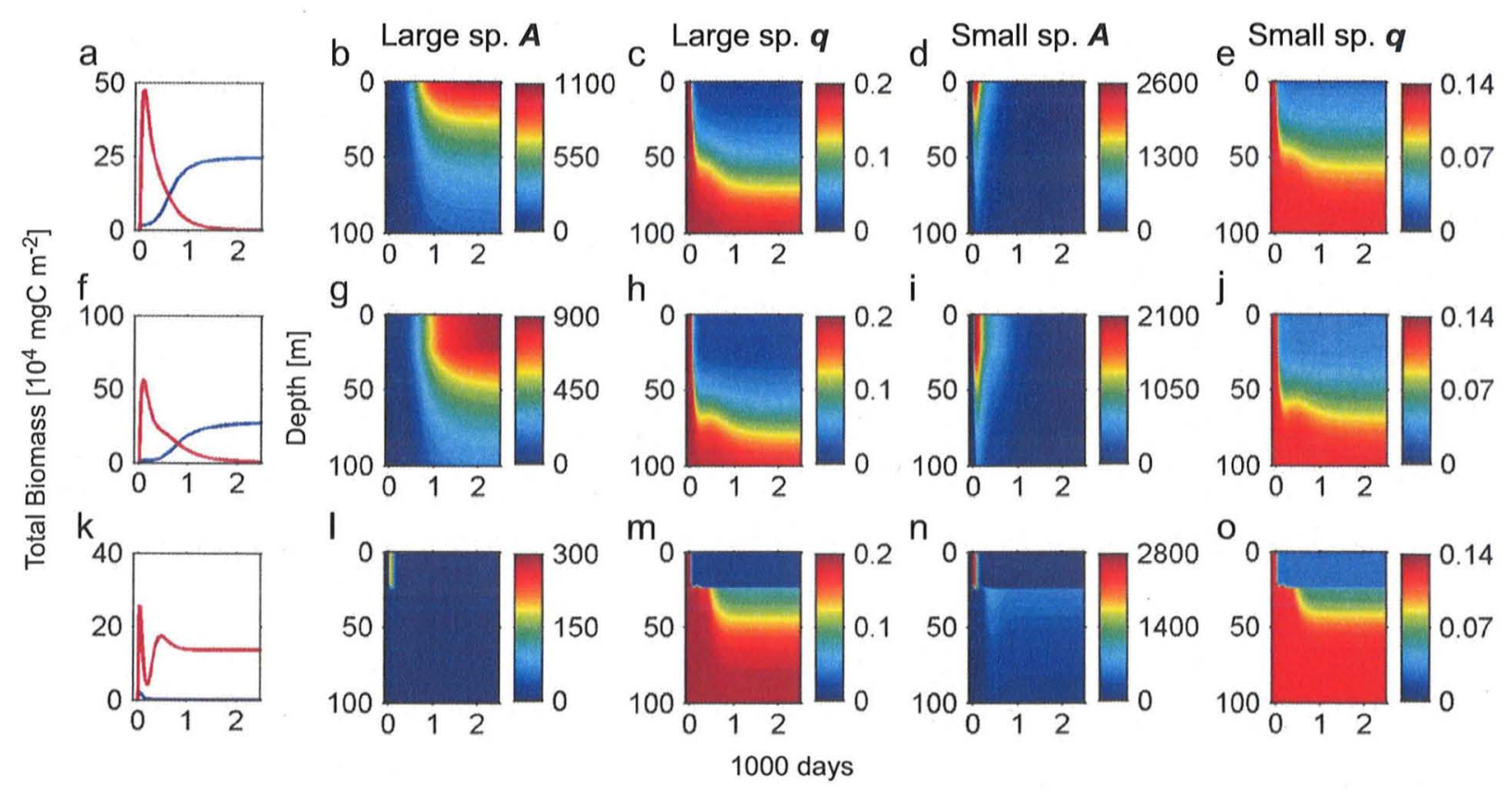

Fig. 4. Spatio-temporal evolution of biomass and quota profiles of large $\left(10^{4} \mu \mathrm{m}^{3}\right)$ and small $\left(10^{2} \mu \mathrm{m}^{3}\right)$ algae species under various mixing regimes when $N_{B}=200 \mathrm{mg}$ $\mathrm{N} \mathrm{m}^{-3}, k_{b g}=0.1 \mathrm{~m}^{-1}, s_{i}=0.2 \mathrm{~m} \mathrm{~d}^{-1}$. (a-e) Homogeneous mixing, $D$ is $50 \mathrm{~m}^{2} \mathrm{~d}^{-1}$ in the entire water column; $(\mathrm{f}-\mathrm{j}) \mathrm{UML}, D_{\text {surf }}$ and $D_{\text {deep }}$ are, respectively, 1000 and $50 \mathrm{~m}^{2} \mathrm{~d}^{-1} ;(\mathrm{k}-0)$ presence of a thermocline, $D_{\text {surf }}, D_{\text {therm }}$ and $D_{\text {deep }}$ are, respectively, $1000,0.1$ and $50 \mathrm{~m}^{2} \mathrm{~d}^{-1}$. (a, f, $\mathrm{k}$ ) Water-column integrated biomass (mg C $\left.\mathrm{m}^{-2}\right),(\mathrm{b}, \mathrm{g}, \mathrm{l})$ and $(d, i, n)$ biomass concentrations $\left(m g \mathrm{Cm}^{-3}\right),(c, h, m)$ and $(e, j, o)$ nutrient cell quotas of large and small species (respectively, blue and red in panel a). 
small species. Equilibrium distribution of dissolved nutrients differed substantially from those in the homogeneous mixing and UML cases, being depleted at the surface mixed layer, suddenly becoming available just below the thermocline and gradually increasing with depth (not shown).

Fig. 5 shows the outcome of competition experiments for the $N_{B}-D_{\text {deep }}$ plane employed in Fig. $3 \mathrm{a}$ and $\mathrm{b}$, but with the presence of an UML (Fig. 5a and b) and a thermocline (Fig. 5d and e). As mentioned above, the effects of an UML are rather marginal (Figs. $3 a$ and $b$ vs. $5 a$ and b). In contrast, the presence of a thermocline imposes a variety of consequences on the outcome of competition. For a range of parameters consisting of relatively high $D$ and low $N_{B}\left(<80 \mathrm{mg} \mathrm{N} \mathrm{m}^{-3}\right)$, the thermocline causes a shift from the dominance of the large to the dominance of the small species (Fig. $3 a$ and b vs. Fig. $5 d$ and e). Under these settings, limited replenishment rate of nutrients at the surface caused by the low permeability at the thermocline leads to transitions from surface to subsurface maximums as shown in Fig. 4l-o, eventually favoring the small species (Fig. $5 \mathrm{~d}$ and e). When the nutrient loading is intermediate $\left(N_{B}=80 \mathrm{mg} \mathrm{N} \mathrm{m}^{-3}\right)$ and phytoplankton do not sink, a founder-controlled zone emerges, in which neither of the competing species can invade the environment driven to the equilibrium by its opponent. In this case, when the small species is the resident, the transition from surface to sub-surface growth occurs, hindering the nutrient transport to the mixed layer and resulting in an equilibrium environment which is not invadable by the large species. When the large species is the resident under the same settings, such a transition does not occur, as shading caused by the surface-dwelling colony is sufficiently high to prevent a deeper colony to form. In turn, the equilibrium environment characterized by an above-thermocline resident population is not favorable for the small species. Note, that while this particular kind of competitive outcome, i.e., the founder controlled dominance (Levin, 1974), is identified readily with the mutual invasibility analysis, the same parameter configurations in 2-species experiments result in a dominance of the species that establishes itself earlier, and competitive exclusion of the other. Finally, when the nutrient loading is relatively high $\left(N_{B}>80 \mathrm{mg} \mathrm{N} \mathrm{m}^{-3}\right)$, the mixing intensity is high and $s_{i}=0$, abovethermocline populations are favored against the below-thermocline populations for both competing species, when they are residents. In addition to the fact that the thermocline keeps the initial above-thermocline population of large species from getting extinct as in the homogeneous mixing case, absence of a belowthermocline population of resident species enables the large species to invade. In contrary, the habitat characterized by the population of the large species above the thermocline is not invadable by the small species; therefore the competitive outcome is shifted in favor of the large species under these settings (Fig. 5 e vs. Fig. 3b). A positive sinking rate facilitates above- to below-thermocline transitions so that the small species remains to be the winner as long as $N_{B}<500 \mathrm{mg} \mathrm{N} \mathrm{m}^{-3}$ (Fig. 5d).

Simulations for obtaining equilibrium environments set by the residents always start with an above-thermocline growth as phytoplankton cells are assumed to be initially at maximum nutrient quotas (Fig. 4). Whether a phase transition from aboveto below-thermocline biomass occurs depends on the population size and nutrient availability above the thermocline. Both of these above- and below-thermocline states tend to be stabilized by positive feedback mechanisms: while a surface growth limits the light penetration to the subsurface and hence increases the rate of nutrient supply from below, a subsurface growth limits the nutrient supply towards upper layers and increases the light supply. Hence, the following question arises: when there exists spatial structuring in the mixing intensities, does the outcome of competition depends on the initial conditions?

The implications of the initial conditions for the outcome of competition were tested in additional simulations, in which the
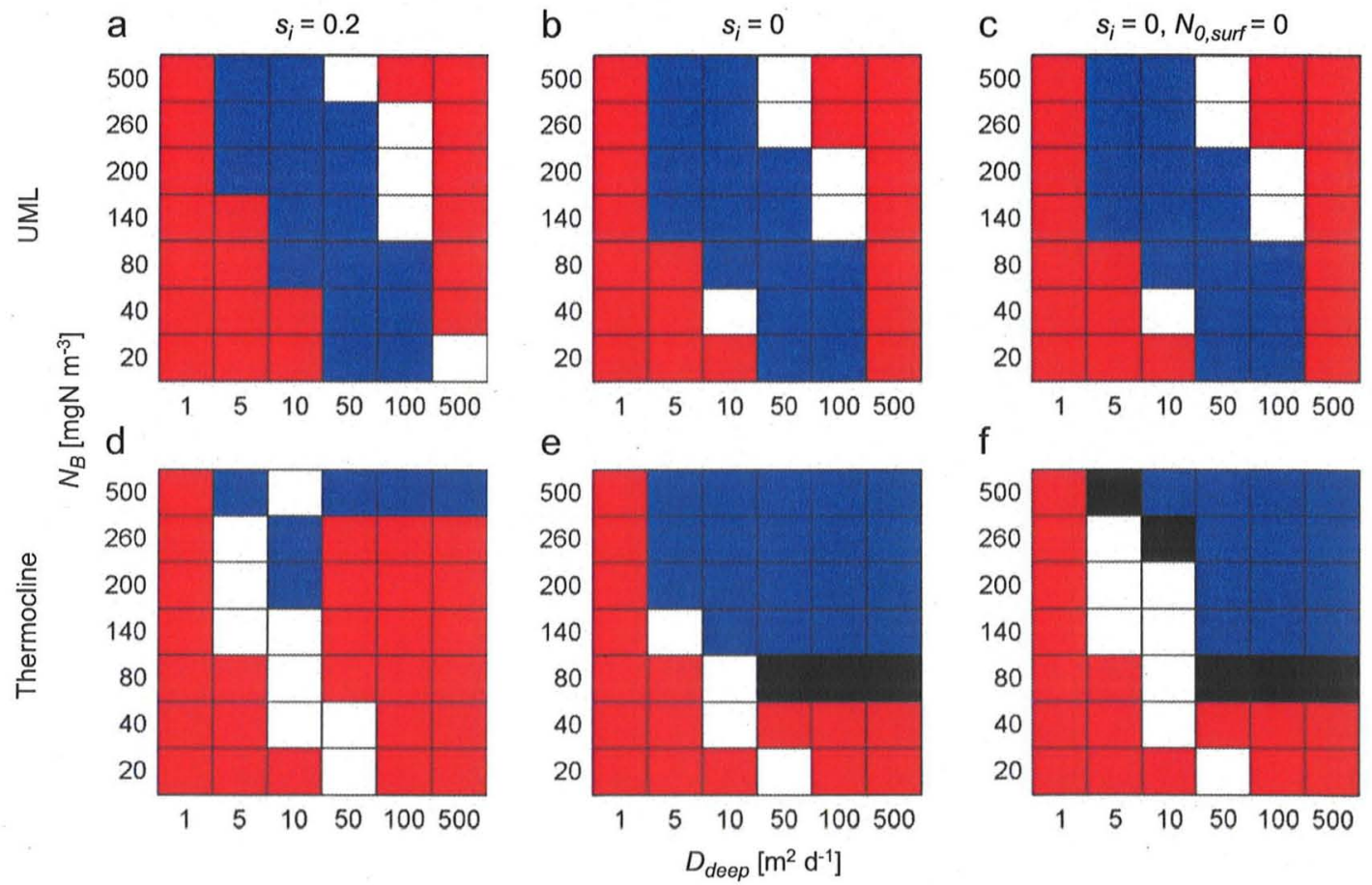

Fig. 5. Results of mutual invasibility experiments conducted with a large $\left(10^{4} \mu \mathrm{m}^{3}\right)$ and small $\left(10^{2} \mu \mathrm{m}^{3}\right)$ species in the $N_{B}-D_{\text {deep }}$ parameter plane, when $k_{b g}=0.1 \mathrm{~m}-1$ and with mixing profiles involving (a-c) a UML; (d-f) a thermocline and when (a, d) cells sink with $s_{i}=0.2 \mathrm{~m} \mathrm{~d}^{-1}$; (b, e) cells are neutrally buoyant; (c-f) $N_{0, \text { suf }}=N(t=0$, $\left.z<z_{\text {mld }}\right)=0$. Color coding is as in Fig. 3, except a new type of outcome shown in black, where the invasion was unsuccessful for both species, therefore the competition is founder-controlled. 
intial distribution of dissolved nutrients was restricted to the deep layers, i.e., $N\left(t=0, z<z_{m l d}\right)=0$. In the case of UML, differences in the initial conditions did not lead to any differences in the competition outcomes (Fig. 5b vs. 5c). On the other hand, in the presence of a thermocline, different initial conditions resulted in different competition outcomes in a total of $6 N_{B}-D_{\text {dee }}$ combinations out of 42 in total (Fig. 5e vs. $5 f$ ). With the original initial conditions, all 6 of them resulted in sustained growth above the thermocline and favored the large species. When there were initially no dissolved nutrients above the thermocline, in 4 out of 6 cases $\left(D_{\text {deep }}=5 \mathrm{~m}^{2} \mathrm{~d}^{-1}, N_{B}=200,260 \mathrm{mg} \mathrm{N} \mathrm{m}^{-3}\right.$; $D_{\text {deep }}=10 \mathrm{~m}^{2} \mathrm{~d}^{-1}, N_{B}=140-200 \mathrm{mg} \mathrm{N} \mathrm{m}^{-3}$ ) a short-lived abovethermocline growth was followed by a phase transition and equilibrium biomasses were below the thermocline, for both of the competing species as residents. Eventually, these 4 cases led to co-existence, as both species were able to invade the equilibrium environment of each other. The remaining 2 parameter combinations $\left(D_{\text {deep }}=5 \mathrm{~m}^{2} \mathrm{~d}^{-1}, \quad N_{B}=500 \mathrm{mg} \mathrm{N} \mathrm{m}{ }^{-3}\right.$. $D_{\text {deep }}=10 \mathrm{~m}^{2} \mathrm{~d}^{-1}, N_{B}=260 \mathrm{mg} \mathrm{N} \mathrm{m}^{-3}$ ) led to founder-controlled dominance. In these cases, the large species did not undergo a phase transition and had a sustained growth above the thermocline, which consequently disabled invasion of the small species. On the other hand, the small species underwent a phase transition and had their equilibrium populations below the thermocline, which did not enable the large species to invade either. Results of this analysis show that, in the presence of a thermocline, outcome of competition depends on the initial conditions.

Finally, we investigated the effects of temporal variations in the mixing profile. Periodic deepening of the mixed layer (hereafter 'periodic mixing') of an UML did not have considerable effects on the outcome of competition (not shown). In contrast, in the presence of a thermocline, the winner was altered, depending on mixing period and particular environmental setting as defined by the parameters $N_{B}$ and $D_{\text {deep }}$ (Fig. 6). For example, at $N_{B}=20 \mathrm{mg}$ $\mathrm{N} \mathrm{m}^{-3}$ and $D_{\text {deep }}=100 \mathrm{~m}^{2} \mathrm{~d}^{-1}$, the small species are dominant in the absence of periodic mixing, $T=\infty$, and at mixing frequencies between 300 and 30 days. However, at mixing periods $T \leq 20$ days, the large species becomes dominant. An environment with higher nutrient concentrations at the bottom, $N_{B}=140 \mathrm{mg} \mathrm{N} \mathrm{m}^{-3}$, and lower mixing intensity below the thermocline, $D_{\text {deep }}=10 \mathrm{~m}^{2} \mathrm{~d}^{-1}$, leads to a contrasting pattern: the large species are dominant in the absence of periodic mixing, the small species are dominant when the mixing periods are rather large $(T=300,100,50$ days $)$ and the large species become dominant again for mixing periods $T \leq 40$ days. Combining the mixing intensity of the first scenario and nutrient concentrations of the second scenario, $N_{B}=140 \mathrm{mg}$ $\mathrm{N} \mathrm{m}^{-3}$ and $D_{\text {deep }}=100 \mathrm{~m}^{2} \mathrm{~d}^{-1}$, provides again a completely different picture: while the periods between mixing events are large (i.e. $T \geq 300$ days) the large species are favored, at intermediate mixing periodicities, i.e., $T=100-30$ days, the large and the small species seem to co-exist (or the competitive exclusion rates are too low) and at $T \leq 20$ days the large species becomes dominant again.

\section{Discussion}

In this study, we isolated the effects of cell size on nutrient utilization abilities of phytoplankton species by allometrically scaling 5 parameters relating nutrient uptake/assimilation of phytoplankton based on established relationships (Table 2). These allometric relationships result in an unconditional dominance of the small species in a conventional chemostat model (Appendix A), which is in agreement with a number of studies asserting that the smaller cell size is advantageous in homogeneous systems (Litchman et al., 2009; Smith and Kalff, 1982; Raven, 1998). Our numerical inspection of phytoplankton competition in spatially structured environments suggests that a lower $q_{\min } / q_{\max }$ ratio associated with larger cell sizes leads to a higher rate of release from nutrient limitation with depth (Fig. 2), which, in turn, can potentially constitute a competitive advantage. If the difference between the nutrient capacities becomes substantial close to the surface where light is abundant, disadvantages of the large species such as lower $\mu_{\infty}$ and lower nutrient uptake rates at the surface can be over-compensated (Section 3.1). The elucidated mechanism of competition, which can also lead to co-existence, differs from the storage-effect (Chesson, 2000), which is considered to be the governing co-existence mechanism in spatially varying environments (Amarasekare et al., 2004; Melbourne et al., 2007). The storage-effect requires presence of sites acting oppositely for competing species either as source or sink terms for the regional population growth rates, while in our case, the spatial segregation between the competing species is minimal, i.e., the depths at which their maximum growth and biomass occur are not distinct, neither for the competitive exclusion (Fig. 2f and g; tand $\mathrm{u}$ ), nor for the co-existence cases (Fig. $2 \mathrm{~m}$ and $\mathrm{n}$ ).

It should be noted that the resulting competitive dominance of the large species under certain environmental settings strictly depends on the decreasing $q_{\min } / q_{\max }$ ratio with cell size. When the allometric exponents for $q_{\max }$ and $q_{\min }$ were assumed to be identical, our additional simulations (not shown) always resulted in the dominance of the smaller species which have substantially higher $\mu_{\infty, i}$ and lower $K_{N}$. This is in accord with Litchman et al. (2009), who claimed that the smaller cells are favored under phosphoruslimitation, as the allometric scaling coefficient of $q_{\max }$ is not greater than that of $q_{\min }$ for phosphorus storage abilities of both marine and freshwater diatoms. Therefore our findings are relevant for the cases in which the nutrient storage abilities differ between competing species as in the case of differentially sized phytoplankton competing for nitrate.

Some motile phytoplankton species are considered to benefit from the heterogeneous distribution of resources throughout the water column by performing diurnal vertical migrations presumably for taking up nutrients at deeper layers during night time and using them at photic zone during day time (Pearre, 2003; Salonen et al., 1984; Sommer and Gliwicz, 1986). Similarly, a passive upward transport of nutrient-rich cells to the epilimnion due to turbulent diffusion might be associated with a greater benefit for the species with greater nutrient storages, which would be in line with our findings that the large species, which has higher $q$ at deep layers (Fig. 2c, j and q), can be dominant over the small species as long as the mixing intensity is sufficiently high (Fig. $2 \mathrm{~g}, \mathrm{n}$ and $\mathrm{u}$ ). We tested the importance of $q_{\max }$, and hence indirectly the importance of this particular mechanism, by considering a hypothetical scenario, where the upper bound of the $q$ of the large species was limited to that of the small species by making the nutrient uptake of the large species cease as soon as $q_{L}=q_{\max , S}$, such that both species have identical $q$ at the deep layers (Appendix B). However, despite losing the advantage of storing higher amounts in the deep layers, the large species kept being competitively dominant against the small species almost for all environmental settings they are dominant according to the standard simulations. This finding suggests that the dominance of the large species in certain environmental settings is not due to their higher $q_{\max }$, hence, the higher nutrient content of large cells in the hypolimnion, which seems to be in line with the conclusion of a recent study by Grover (2009), where it was found that a higher $q_{\max }$ do not contribute much to the competitive fitness.

Effects of mixing intensity on the outcome of competition depend on the system parameters, such as background turbidity and nutrient concentrations (Fig. 3). When background turbidity and nutrient $\left(\mathrm{NO}_{3}-\mathrm{N}\right)$ concentrations are low, as is typical for 
a
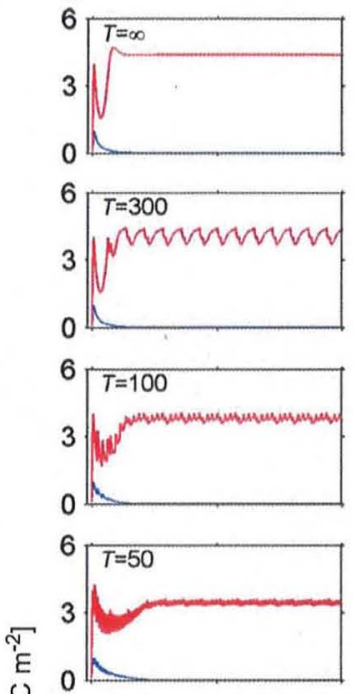

O) 6
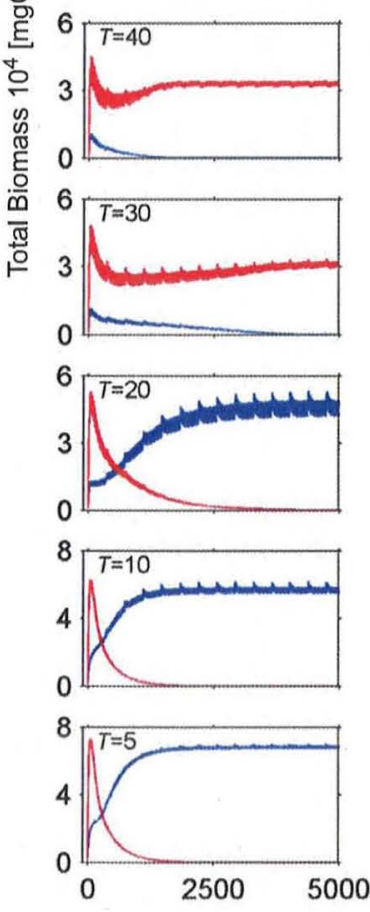

b
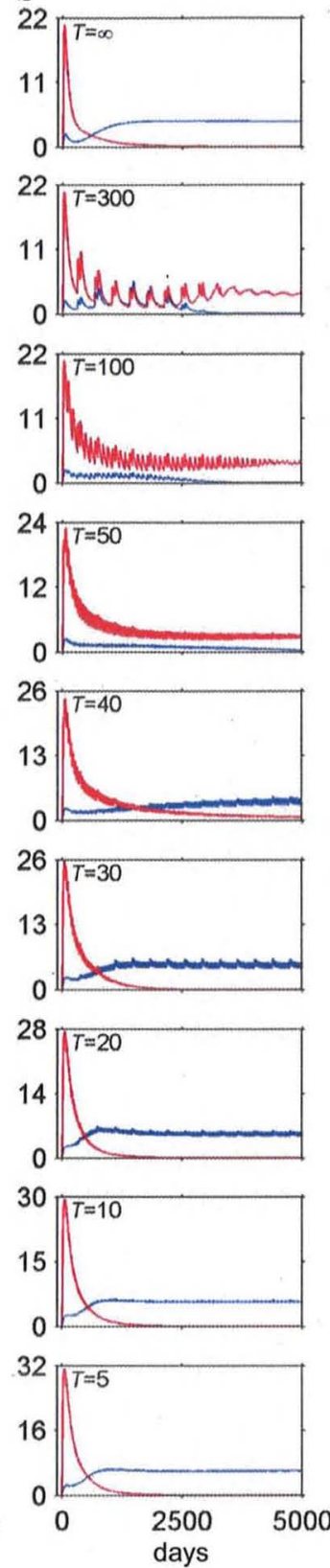

$\mathrm{C}$
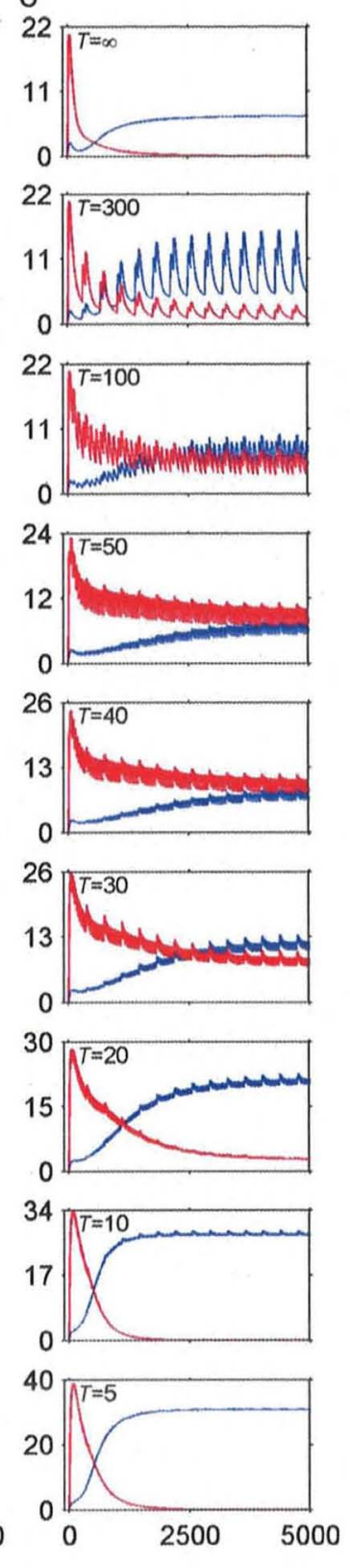

Fig. 6. Effects of mixing period, $T$, when there is a thermocline at various $N_{B}\left(\mathrm{mg} \mathrm{N} \mathrm{m}^{-3}\right)-D_{\text {deep }}\left(\mathrm{m}^{2} \mathrm{~d}^{-1}\right)$ combinations. $T=\infty$ indicates temporally homogeneous mixing. $k_{b g}=0.1 \mathrm{~m}^{-1}$ and $s_{i}=0$ for all simulations.

clear ocean conditions (Gruber, 2008), large cells are promoted by intermediate-to-high mixing intensities (Fig. 3a and b). On the other hand, when the turbidity and nutrient concentrations are high, characterizing coastal marine systems (Smith, 2003), rapid mixing increases light limitation further and leads to extinction of large cells (Fig. 3c and d). Other factors such as selective zooplankton feeding favoring large cells (Jiang et al., 2005) and differential sedimentation rates and light utilization abilities favoring small cells (Smayda, 1971; Schwaderer et al., 2011) further complicate the process of algal size selection. Nevertheless our findings shed light on the effects of cell size on algal resource competition dynamics in incompletely mixed systems, which certainly plays a role in the formation of community assemblies in the field (Follows et al., 2007; Tilman 2004).
Our findings demonstrate that spatial heterogeneities in the mixing regime can also have context-dependent effects on algal competition. The presence of a thermocline alters the outcome of competition in opposing ways, depending on the environmental setting: (i) by preserving the large species which would otherwise be extinct due to light limitation at very high mixing intensities, or by leading to nutrient depletion at the surface layers and transitions from surface to subsurface biomasses that favor the small species which perform better when the nutrient supply rates are low. Surface and sub-surface maxima are supported by feed-back mechanisms as light and nutrients are found in opposing gradients: growth at the surface reduces the availability of light, hence, growth at deeper layers which consequently increases nutrient supply from the bottom, and vice versa 
(Yoshiyama and Nakajima, 2002). Such systems with different equilibrium solutions, each supported by their own feedback mechanisms, are known to potentially exhibit alternative stable states behavior, in which, gradual changes in parameter values can cause irreversible catastrophic shifts between states (Scheffer et al., 2001). Yoshiyama and Nakajima (2002) previously demonstrated that gradual changes in the incident light intensity and nutrient concentration at the bottom can result in catastrophic shifts between surface and sub-surface maximums. Here we have shown that, for a certain $N_{B}-D$ parameter plane, occurrence of these transitions depends on the initial conditions, and that, such transitions can lead to alteration of the species size selection as well as emergence of founder-control competitive outcome (Levin, 1974). Therefore, the presence of a thermocline becomes an additional source of complexity for the explanation of phytoplankton size structure patterns observed in nature, and requires further attention. For the UML, such transitions also occur, but only for the very low mixing intensities, e.g., $D_{\text {deep }}=1 \mathrm{~m}^{2} \mathrm{~d}^{-1}$, confirming Ryabov et al. (2010), who reported that occurrence of this phenomenon requires low rates of nutrient transport from below and a sufficient light climate below the UML, that is realized within a limited parameter range. These transitions do not result in the alteration of the winner (Fig. $5 \mathrm{a}$ and b), as the small species are dominant anyway when the mixing intensity is low and homogeneous throughout the water column (Fig. 3a and b).

Global warming is anticipated to enhance the stability of stratification and hence resistance to mixing (Lehman, 2002; Coats et al., 2006), that can, among other potential effects, correspond to longer periods between mixing events. The reduced frequency of mixing events, which would result in a lower supply of nutrients to the surface on average, has been thought to promote the small algal cells, as small cells are better competitors in nutrient scarce conditions (Winder et al., 2009; Falkowski and Oliver, 2007). However, the temporal variability in the nutrient concentrations at the surface induced by mixing events can have additional effects on the selection of cell size, as it has been shown that cells with higher storage capacities can benefit from an intermediate periodicity of nutrient pulses, by means of sustained growth during periods of nutrient scarcity (Grover, 1991a; Litchman et al., 2009). An explicit consideration of temporal changes in the turbulent mixing profiles enables combination of these 2 different mechanisms, separately attributed to the potential effects of climate warming so far in the literature, i.e., change of average nutrient supply rates to the surface and the periodicity of nutrient pulses, that are thought to affect the selection of algal cell size. Moreover, this approach additionally incorporates the effects of changes in the light limitation experienced by cells as a result of re-distribution of their biomass during the mixing event, which has not been considered in this context so far. According to our simulations, periodic mixing does not have considerable effects in a 2-layer UML setting. However, as the presence of a thermocline creates large gradients in the distribution of nutrient availabilities that are found either in bound or dissolved form, a sudden deepening of the thermocline not only redistributes the biomass and changes the light climate as in the case of the deepening of a UML, but also entrains the nutrient pool just below the thermocline. Periodic perturbation of 4 variables, $A_{i}, B_{i}, N$ and indirectly $I$, thus has dramatic effects on the outcome of competition (Fig. 6). Our findings suggest that effects of such perturbations on algal size selection cannot be summarized as a simple function of periodicity, as competitive outcomes between small and large species were altered in either direction, and either rather abruptly or rather gradually with changing periodicities at different environmental settings characterized by nutrient loading and background mixing intensity. Interestingly, competition outcome was shown to possibly differ between the steady state environments $(T=\infty)$ and at mixing periodicities approximately corresponding to annual cycles ( $T=300$ days) that characterize a vast number of ecosystems, pointing to another potential source of uncertainty for predicting the patterns in nature based on steady state solutions.

\section{Conclusions}

Our findings illustrate the role of cell size on algal competitive abilities in incompletely mixed systems. While the higher nutrient affinity and growth rate of the small species makes them better competitors in well mixed environments, lower $q_{\min } / q_{\max }$ ratio of the large species results in a higher rate of relieve from nutrient limitation with depth in the heterogeneous systems and potentially over-compensate their disadvantages if the environmental configurations lead to a positioning of this deviation close to the surface. Mixing intensity, nutrient concentration at the bottom, background turbidity and spatial or spatio-temporal variability in the mixing regime were shown to be critical parameters effecting the size selection of algae. In this study, we chose to focus on 2 algal species with particular sizes, in order to identify the key mechanisms and test them extensively under various environmental settings. Having gained fundamental insights into the effects of cell size on the algal competition in a heterogeneous environment in this study, a systematic analysis of competition dynamics among a broader range of cell sizes remains to be a future task. Moreover, there have been recent advances in quantitatively relating zooplankton food selectivity to the food quantity and quality in terms of nutrimental values (Mitra and Flynn, 2006) and cell size as a measure of palatability (Fuchs and Franks, 2010), providing excellent opportunities to complement the bottom-up approach presented here. As zooplankton can also have indirect effects on the competition dynamics by changing the elemental ratios in the environment (Grover, 2002), and since these changes are likely to be different in shallow and deep layers, an explicit consideration of the vertical dimension can prove to be beneficial.

\section{Acknowledgments}

O.K. was supported by the Deutsche Forschungsgemeinschaft (DFG) within the AQUASHIFT program (SPP 1162, PE 701/2-2). The authors wish to thank two referees for their detailed comments that helped to substantially improve this paper.

\section{Appendix A. Analysis of the allometrically estimated $R^{*}$ for a well-mixed system}

In order to gain insight into the competitive outcome of the set of physiological processes and parameters considered with a vertically resolved model (Eqs. (1)-(4), (6) and (7), Tables 1 and 2 ) in a conventional well mixed chemostat forced with a dilution rate $D^{\prime}$ (e.g., similar to that described by Ducobu et al. (1998)), Eqs. (1)-(3) can be reformulated as follows:

$$
\begin{aligned}
& \frac{d A}{d t}=p(I, q)\left(1-l_{r}\right) A-\left(l_{d}+D^{\prime}\right) A \\
& \frac{d B}{d t}=v(N, q) A-\left(p l_{r}+l_{d}+D^{\prime}\right) B \\
& \frac{d N}{d t}=\gamma_{r} l_{r} p(I, q) A q+\gamma_{d} l_{d} B-v(N, q) A+D^{\prime}\left(N_{B}-N\right)
\end{aligned}
$$


Recalling $q=B / A$ and applying the quotient rule, we get

$\frac{d q}{d t}=v(N, q)-p(I, q) q$

At steady state Eq. (A1) becomes

$p\left(I, q^{*}\right)\left(1-l_{r}\right)=M$

where, $M=l_{d}+D^{\prime}$ and $q^{*}$ denoting the nutrient quota at equilibrium. The system described by Eqs. (A4) and (A5) is essentially the classical variable internal stores model of a well-mixed chemostat (Grover, 1991a; Morel, 1987; Ducobu et al., 1998). In order to keep the representation identical to that of Ducobu et al. (1998), the production rate $p$ previously described in Eq. (4) can be reformulated and substituted in Eq. (A5) as

$\mu^{\prime}\left(\frac{q^{*}-q_{\min }}{q^{*}}\right)=M$

where $\mu^{\prime}$ is a composite parameter accounting for respiratory losses and light limitation in addition to the $\mu_{\infty}$ itself

$\mu^{\prime}=\mu_{\infty}\left(\frac{I}{I+K_{I}}\right)\left(1-l_{r}\right)$

From Eq. (A6), the steady state nutrient quota, $q^{*}$ is found as

$q^{*}=\frac{\mu^{\prime} q_{\min }}{\mu^{\prime}-M}$

The change of maximum uptake rate, $v_{\max }$, with nutrient quota, $q$, described in Eq. (7) can be also reformulated in the form:

$v_{\text {max }, i}(q)=a-b q$

where

$a=\frac{v_{\max } q_{\max }}{q_{\max }-q_{\min }}$ and $b=\frac{v_{\max }}{q_{\max }-q_{\min }}$

Then the equilibrium nutrient uptake rate, based on Eq. (6) becomes

$v_{i}\left(N, q^{*}\right)=\left(a-b q^{*}\right) \frac{N^{*}}{N^{*}+K_{N}}$

Substituting Eqs. (A8) and (A10) into Eq. (A4) at steady state yields the equilibrium resource concentration as

$R^{*}=\frac{K \mu^{\prime} M q_{\min }}{a\left(\mu^{\prime}-M\right)-\mu^{\prime} q_{\min }(b+M)}$

which is identical to the $R^{*}$ derived by Ducobu et al. (1998) in form, where our $\mu^{\prime}$ corresponds to their $\left(\mu_{m}^{\prime}\right)$ and our $M$ corresponds to their $(D)$.

With the parameters $K, \mu_{\infty}, q_{\min }, q_{\max }$ and $v_{\max H}$ allometrically scaled according to the coefficients provided by Litchman et al. (2009) and for any combination of $M$ and $I$ the small species $\left(V=10^{2} \mu \mathrm{m}^{3}\right)$ always have lower $N^{*}$ than that of the large species $\left(V=10^{4} \mu \mathrm{m}^{3}\right)$ as exemplified in Fig. A1.

\section{Appendix B. Role of cells with $\boldsymbol{q}_{\max }$ at the deep layers on the outcome of competition}

The higher $q_{\max }$ of the large species may potentially cause the large species to benefit from the upward transport of nutrientrich cells more than the small species. In order to test the role of differences in the $q_{\max }$ of competing species on the outcome of competition, we consider a hypothetical scenario where the upper boundary of $q_{L}$ is limited to $q_{\max , S}$ by making the maximum nutrient uptake rate of the large species rapidly approach 0 when $q_{L}$ approaches $q_{\max , S}$ by modifying the quota-maximum uptake rate relation (Eq. (7)) as

$v_{\max , L}(N, q)=v_{\max , L}\left(\frac{q_{\max , L}-q_{L}}{q_{\max , L}-q_{\min , L}}\right)\left(0.5-0.5 \tanh \left(1000\left(q_{L}-q_{l m}\right)\right)\right)$
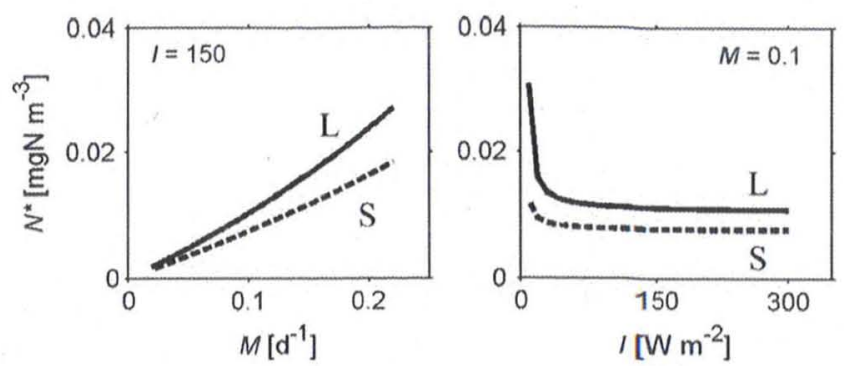

Fig. A1. Equilibrium resource concentration, $N^{*}$, calculated for the small $\left(10^{2} \mu \mathrm{m}^{3}\right.$ dashed line) and large species $\left(10^{4} \mu \mathrm{m}^{3}\right.$, solid line) over a range of $M$ (death+ dilution rate) and $I$ (irradiance) values.
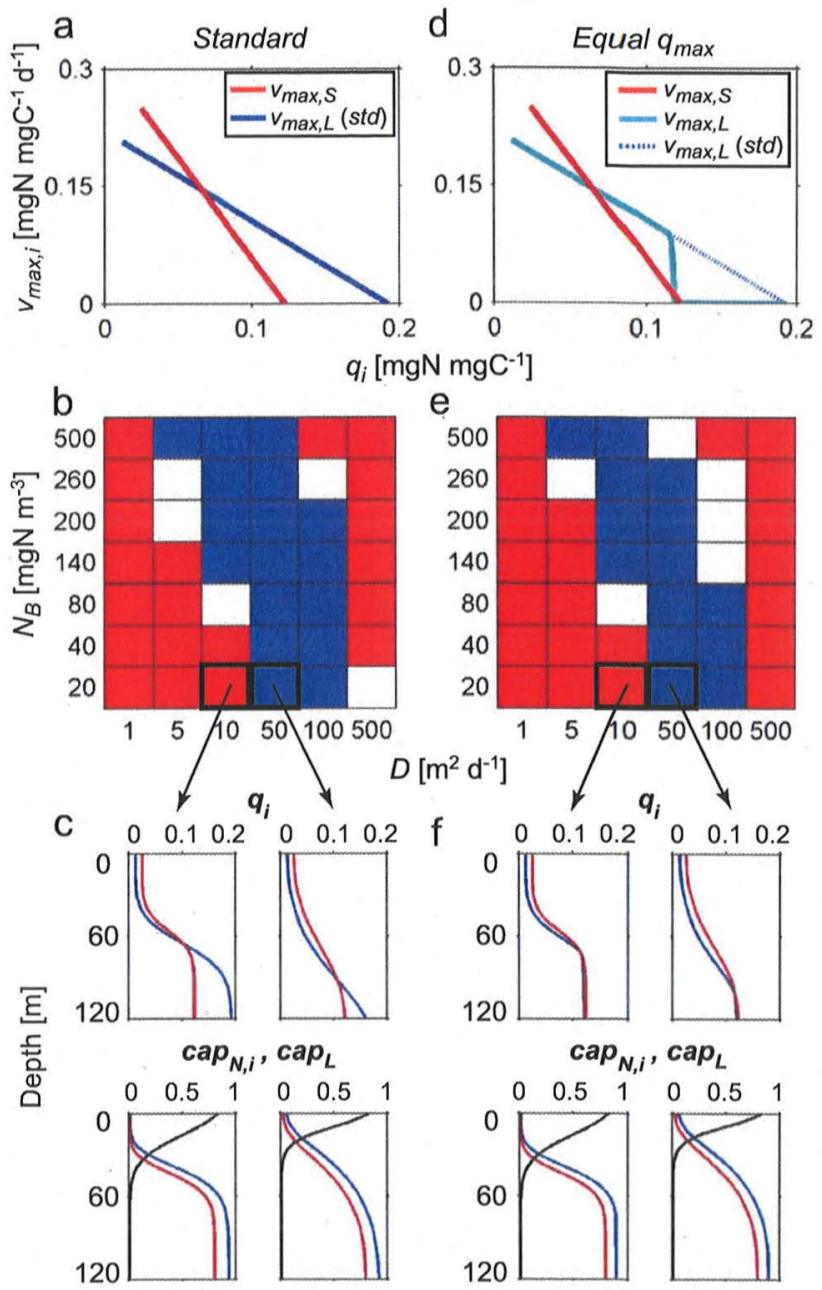

Fig. B1. Change of maximum uptake rate, $v_{\max , i}$ with nutrient storages, $q_{i}$ (a, d) results of mutual invasibility experiments ((b, e) $s_{i}=0.2 \mathrm{~m} \mathrm{~d}^{-1}, k_{b g}=0.1 \mathrm{~m}^{-1}$, everything else same as in Fig. 3) and vertical profiles of nutrient quotas and resulting nutrient-light capacities for 2 example $N_{B}-D$ pairs (c, f). Panels (a-c) the standard $q_{\max }$ and $q_{\min }$ values based on allometric relationships, $(\mathrm{d}-\mathrm{f})$ the upper bound of $q_{L}$ is limited to $q_{\text {max }, S}$. Note that panel $\mathrm{b}$ is identical to Fig. 3a and the profiles in panel $c$ are present in Fig. 2, but they are shown here again for facilitating the comparison.

where $q_{l m}$ was defined to be $q_{\min , L}+\left(q_{\max , S}-q_{\min , L}\right) 0.95$, or equivalently, $q_{l m} \approx q_{\max , s}$. The second part of Eq. (B1) hyperbolically approaches 1 as $q_{L}$ decreases below $q_{l m}$ and 0 as $q_{L}$ increases above $q_{l n n}$ (Fig. B1d). Limiting the nutrient uptake rate of the large species in such a way has slightly negative effects on their 
competitive performance: in 5 out of $42 N_{B}-D$ combinations considered previously in Fig. 3a, the competition outcome shifts either from co-existence to dominance of small species or dominance of large species to co-existence (Fig. B1e). As the nutrient uptake stops when $q_{L}$ approaches $q_{\max , S}$, both species end up having equal nutrient quotas in the deep layers (Fig. B1f). However, despite losing the advantage of being able to store higher amounts of nutrients at the deep layers, deviation of $q_{L}$ from $q_{\min , L}$ with depth still occurs at a higher rate than the deviation of $q_{s}$ from $q_{\min , S}$, as reflected by the nutrient capacity curves (Fig. B1f). In turn, as was the case for the standard scenario, increasing the $N_{B}$ or $D$ positions this nutrient capacity advantage of the large species closer to the surface, where the higher yield of interaction with the light capacity curve results in a higher ultimate resource capacity advantage, which can, if sufficiently high, over-compensate the lower growth rate disadvantage of the large species. Results of this experiment suggest that the differences between the nutrient content of the cells diffusively transported from the deep layers do not substantially affect the outcome of competition.

\section{References}

Amarasekare, P., Hoopes, M.F., Mouquet, N., Holyoak, M., 2004. Mechanisms of coexistence in competitive metacommunities. Am. Nat. 164, 310-326.

Blanton, J.O., 1973. Vertical entrainment into epilimnia of stratified lakes. Limnol Oceanogr. 18, 697-704

Chesson, P., 2000. General theory of competitive coexistence in spatially-varying environments. Theor. Popul. Biol. 58, 211-237.

Coats, R., Perez-Losada, J., Schladow, G., Richards, R., Goldman, C., 2006. The warming of Lake Tahoe. Climatic Change 76, 121-148.

Droop, M.R., 1973. Some thoughts on nutrient limitation in algae. J. Phycol. 9, 264-272.

Ducobu, H., Huisman, J., Jonker, R.R., Mur, L.R., 1998. Competition between a prochlorophyte and a cyanobacterium under various phosphorus regimes: comparison with the Droop model. J. Phycol. 34, 467-476.

Elser, J.J., George, N.B., 1993. The stoichiometry of N and P in the pelagic zone of the Castle Lake, California. J. Plankton Res. 15, 977-992.

Falkowski, P.G., Oliver, M.J., 2007. Mix and match: how climate selects phytoplankton. Nat. Rev. Microbiol. 5, 813-819.

Follows, M.J., Dutkiewicz, S., Grant, S., Chisholm, S.W., 2007. Emergent biogeography of microbial communities in a model ocean. Science 315, 1843-1846.

Fuchs, H.L., Franks, P.J.S., 2010. Plankton community properties determined by nutrients and size-selective feeding. Mar. Ecol. Prog. Ser. 413, 1-15.

Geritz, S.A.H., Kisdi, E., Meszena, G., Metz, J.A.J., 1998. Evolutionarily singular strategies and the adaptive growth and branching of the evolutionary tree. Evol. Ecol. 12, 35-57.

Grover, J.P., 1991a. Resource competition in a variable environmentphytoplankton growing according to the variable-internal stores model. Am. Nat. 138, 811-835.

Grover, J.P., 1991b. Dynamics of competition among microalgae in variable environments-experimental tests of alternative models. Oikos 62, 231-243.

Grover, J.P., 2002. Stoichiometry, herbivory and competition for nutrients: simple models based on planktonic ecosystems. J. Theor. Biol. 214, 599-618.

Grover, J.P., 2009. Is storage an adaptation to spatial variation in resource availability? Am. Nat. 173, E44-E61.

Gruber, N., 2008. The marine nitrogen cycle: overview of distributions and processes. In: Capone, D.G., Bronk, D.A., Mulholland, M.R., Carpenter, E.J. (Eds.), Nitrogen in the Marine Environment, 2nd edition Elsevier, Amsterdam, pp. 1-50.

Hsu, S.-B., Jiang, J., Wang, F.-B., 2010. On a system of reaction-diffusion equations arising from competition with internal storage in an unstirred chemostat J. Differential Equations 248, 2470-2496.

Huisman, J., Weissing. F.J., 1995. Competition for nutrients and light in a mixed water column-a theoretical-analysis. Am. Nat. 146, 536-564.

Huisman, J., van Oostveen, P., Weissing, F.J., 1999a. Critical depth and critical turbulence: two different mechanisms for the development of phytoplankton blooms. Limnol. Oceanogr. 44, 1781-1787.

Huisman, J., van Oostveen, P., Weissing, F.J., 1999b. Species dynamics in phytoplankton blooms: incomplete mixing and competition for light. Am. Nat. 154, 46-68.

Huisman, J., Thi, N.N.P., Karl, D.M., Sommeijer, B., 2006. Reduced mixing generates oscillations and chaos in the oceanic deep chlorophyll maximum. Nature 439, 322-325.

Irwin, A.J., Finkel, Z.V., Schofield, O.M.E., Falkowski, P.G., 2006. Scaling-up from nutrient physiology to the size-structure of phytoplankton communities. J. Plankton Res. 28, 459-471.

Jäger, C.G., Dichl, S., Emans, M., 2010. Physical determinants of phytoplankton production, algal stoichiometry, and vertical nutrient fluxes. Am. Nat. 175, E51-E104.
Jiang, L., Schofield, O.M.E., Falkowski, P.G., 2005. Adaptive evolution of phytoplankton cell size. Am. Nat. 166, 496-505.

Klausmeier, C.A., 2008. Floquet theory: a useful tool for understanding nonequilibrium dynamics. Theor. Ecol. 1, 153-161

Klausmeier, C.A., Litchman, E., 2001. Algal games: the vertical distribution of phytoplankton in poorly mixed water columns. Limnol. Oceanogr. 46, 1998-2007.

Lehman, J.T., 2002. Mixing patterns and plankton biomass of the St. Lawrence Great Lakes under climate change scenarios. J. Great Lakes Res. 28, 583-596.

Levin, S.A., 1974. Dispersion and population interactions. Am. Nat. 108, 207-228.

Li, Y.H., 1973. Vertical eddy diffusion coefficient in Lake Zurich. Hydrologie 35 $1-7$

Li, W.K.W., 2002. Macroecological patterns of phytoplankton in the northwestern North Atlantic Ocean. Nature 419, 154-157.

Litchman, E., Klausmeier, C.A., 2008. Trait-based community ecology of phytoplankton. Annu. Rev. Ecol. Evol. Syst. 39, 615-639.

Litchman, E., Klausmeier, C.A., Yoshiyama, K., 2009. Contrasting size evolution in marine and freshwater diatoms. Proc. Natl. Acad. Sci. USA 106, 2665-2670.

MacArthur, R.H., Levins, R., 1967. Limiting similarity, convergence and divergence of coexisting species. Am. Nat. 101, 377-385.

Melbourne, B.A., Cornell, H.V., Davies, K.F., Dugaw, C.J., Elmendorf, S., Freestone, A.L Hall, R.J., Harrison, S., Hastings, A., Holland, M., Holyoak, M., Lambrinos, J. Moore, K., Yokomizo, H., 2007. Invasion in a heterogeneous world: resistance, coexistence or hostile takeover? Ecol. Lett. 10, 77-94.

Metz, J.A.J., Nisbet, R.M., Geritz, S.A.H., 1992. How should we define fitness for general ecological scenarios. Trends Ecol. Evol. 7, 198-202.

Mitra, A., Flynn, K.J., 2006. Accounting for variation in prey selectivity by zooplankton. Ecol. Model. 199, 82-92.

Montagnes, D.J.S., Franklin, D.J., 2001. Effect of temperature on diatom volume growth rate, and carbon and nitrogen content: reconsidering some paradigms. Limnol. Oceanogr. 46, 2008-2018.

Morel, F.M.M., 1987. Kinetics of nutrient-uptake and growth in phytoplankton. J. Phycol. 23, 137-150.

Pearre, S., 2003. Eat and run? The hunger/satiation hypothesis in vertical migration: history, evidence and consequences. Biol. Rev. 78, 1-79

Raven, J.A., 1998. The twelfth Tansley lecture. Small is beautiful: the picophytoplankton. Funct. Ecol. 12, 503-513.

Reynolds, C.S., 1989. Physical determinants of phytoplankton succession. In: Sommer, U. (Ed.), Plankton Ecology: Succession in Plankton Communities. Springer-Verlag, Berlin.

Rhee, G.Y., Gotham, I.J., 1981. The effect of environmental-factors on phytoplankton growth-light and the interactions of light with nitrate limitation. Limnol. Oceanogr. 26, 649-659.

Richardson, T.L., Jackson, G.A., 2007. Small phytoplankton and carbon export from the surface ocean. Science 315, 838-840.

Rodriguez, J., Tintore, J., Allen, J.T., Blanco, J.M., Gomis, D., Reul, A., Ruiz, J. Rodriguez, V., Echevarria, F., Jimenez-Gomez, F., 2001. Mesoscale vertical motion and the size structure of phytoplankton in the ocean. Nature 410 360-363.

Ryabov, A.B., Rudolf, L., Blasius, B., 2010. Vertical distribution and composition of phytoplankton under the influence of an upper mixed layer. J. Theor. Biol. 263, 120-133.

Ryabov, A.B., Blasius, B., 2011. A graphical theory of competition on spatial resource gradients. Ecol. Lett. 14, 220-228.

Salihoglu, B., Garcon, V., Oschlies, A., Lomas, M.W., 2008. Influence of nutrient utilization and remineralization stoichiometry on phytoplankton species and carbon export: a modeling study at BATS. Deep-Sea Res. Part I-Oceanogr. Res. Pap. 55, 73-107.

Salonen, K., Jones, R.I., Arvola, L., 1984. Hypolimnetic phosphorus retrieval by diel vertical migrations of lake phytoplankton. Freshwater Biol. 14, 431-438.

Scheffer, M., Carpenter, S., Foley, J.A., Folke, C., Walker, B., 2001. Catastrophic shifts in ecosystems. Nature $413,591-596$.

Schwaderer, A.S., Yoshiyama, K., Pinto, P.T., Swenson, N.G., Klausmeier, C.A. Litchman, E., 2011. Eco-evolutionary differences in light utilization traits and distributions of freshwater phytoplankton. Limnol. Oceanogr. 56, 589-598.

Smayda, T.J., 1971. Normal and accelerated sinking of phytoplankton in the sea Mar. Geol. 11, 105-122

Smith, J.M., Price, G.R., 1973. Logic of animal conflict. Nature 246, 15-18.

Smith, R.E.H., Kalff, J., 1982. Size-dependent phosphorus uptake kinetics and cell quota in phytoplankton. J. Phycol. 18, 275-284.

Smith, V.H., 2003. Eutrophication of freshwater and coastal marine ecosystems-a global problem. Environ. Sci. Pollut. Res. 10, 126-139.

Sommer, U., 1985. Comparison between steady-state and non-steady state competition-experiments with natural phytoplankton. Limnol. Oceanogr. 30, 335-346.

Sommer, U., Gliwicz, Z.M., 1986. Long-range vertical migration of volvox in tropical Lake Cahora Bassa (Mozambique). Limnol. Oceanogr. 31, 650-653.

Stolte, W., Riegman, R., 1995. Effect of phytoplankton cell-size on transient-state nitrate and ammonium uptake kinetics. Microbiol.-UK 141, 1221-1229.

Strathmann, R.R., 1967. Estimating organic carbon content of phytoplankton from cell volume or plasma volume. Limnol. Oceanogr. 12, 411.

Sunda, W.G., Hardison, D.R., 2010. Evolutionary tradeoffs among nutrient acquisition, cell size, and grazing defense in marine phytoplankton promote ecosystem stability. Mar. Ecol. Prog. Ser. 401, 63-76. 
Tett, P., Edwards, A., Jones, K., 1986. A model for the growth of shelf-sea phytoplankton in summer. Estuarine Coastal Shelf Sci. 23, 641-672.

Tilman, D., 1980. Resources-a graphical-mechanistic approach to competition and predation. Am. Nat. 116, 362-393.

Tilman, D., 2004. Niche tradeoffs, neutrality, and community structure: a stochastic theory of resource competition, invasion, and community assembly. Proc. Natl. Acad. Sci. USA 101, 10854-10861.

Verdy, A., Follows, M., Flierl, G., 2009. Optimal phytoplankton cell size in an allometric model. Mar. Ecol. Prog. Ser. 379, 1-12.
Winder, M., Reuter, J.E., Schladow, S.G., 2009, Lake warming favours small-sized planktonic diatom species. Proc. R. Soc. B-Biol. Sci. 276, 427-435.

Yoshiyama, K., Nakajima, H., 2002. Catastrophic transition in vertical distributions of phytoplankton: alternative equilibria in a water column. J. Theor. Biol. 216 , 397-408.

Yoshiyama, K., Mellard, J.P., Litchman, E., Klausmeier, C.A., 2009. Phytoplankton competition for nutrients and light in a stratified water column. Am. Nat. 174 190-203. 